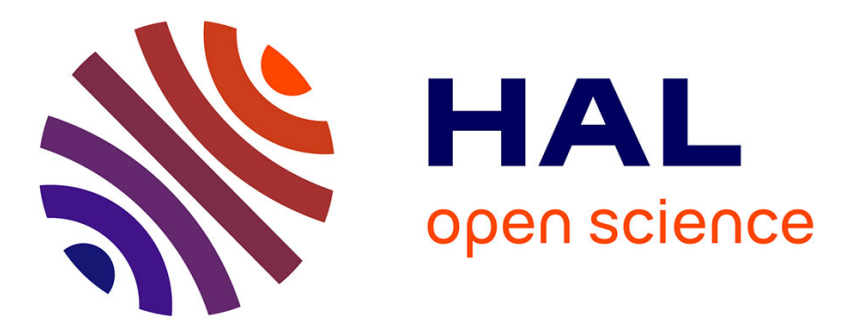

\title{
Aurora borealis systems in the German-Russian world in the first half of the eighteenth century: the cases of Friedrich Christoph Mayer and Leonhard Euler
}

E. Chassefière

\section{- To cite this version:}

E. Chassefière. Aurora borealis systems in the German-Russian world in the first half of the eighteenth century: the cases of Friedrich Christoph Mayer and Leonhard Euler. Annals of Science, 2021, pp.1-35. 10.1080/00033790.2021.1891284 . hal-03182107

\section{HAL Id: hal-03182107 \\ https: / hal.sorbonne-universite.fr/hal-03182107}

Submitted on 26 Mar 2021

HAL is a multi-disciplinary open access archive for the deposit and dissemination of scientific research documents, whether they are published or not. The documents may come from teaching and research institutions in France or abroad, or from public or private research centers.
L'archive ouverte pluridisciplinaire HAL, est destinée au dépôt et à la diffusion de documents scientifiques de niveau recherche, publiés ou non, émanant des établissements d'enseignement et de recherche français ou étrangers, des laboratoires publics ou privés. 


\title{
Aurora borealis systems in the German-Russian world in the first half of the 18th century: The cases of Friedrich Christoph Mayer and Leonhard Euler
}

\author{
E. CHASSEFIÈRE
}

SYRTE, Observatoire de Paris-Université PSL, CNRS, Sorbonne Université, 61 avenue de l'Observatoire, 75014 Paris, France. Tel.: 01405122 03, e-mail: eric.chassefiere@ obspm.fr.

Résumé: We are interested in the case of Friedrich Christoph Mayer, who in the 1720s, while at the Imperial Academy of Sciences in St. Petersburg (in Latin Academiae scientiarum imperialis Petropolitanae), developed a system of the aurora borealis, as well as a mathematical method for calculating the height of the aurora from the geometrical characteristics of the auroral arc. Mayer, encountering a major contradiction in his system which placed the aurora at the height of the clouds, whereas his mathematical method led to an altitude a hundred times higher, never applied his method to concrete cases to deduce the height of the aurora, and quickly lost interest in their detailed description, a task that was nevertheless assigned to him at the St. Petersburg Observatory. Jean-Jacques Dortous de Mairan suggests that Mayer's abandonment was due to his lack of confidence in observations. We set Mayer's case against that of Leonhard Euler who, working with Mayer and being aware of the great height of the aurora, later developed a system of the aurora borealis that was compatible with the observational fact. We put forward possible hypotheses to explain 
Mayer's disinterest in the observation of the aurora and in the mathematical method he himself had developed.

Key words: Friedrich Christoph Mayer, Leonhard Euler, Christian Wolff, Imperial Academy of Sciences of St. Petersburg, Northern lights.

\section{Introduction}

In January 1724, Peter the Great presented a document to the Russian Senate describing his project for an imperial academy ${ }^{1}$. He had previously met several times in the 1710 s with Gottfried Wilhelm Leibniz - the father of the Berlin Academy of Science and Fine Arts, founded in 1700 - with whom he discussed how Russia could be rapidly turned into a European state. Among the essential tasks assigned by Leibniz to the new academy was to attract much-needed competent foreigners. Indeed, unlike the main academies that were being created at the same time, or that had been set up in the second half of the 17th century (e.g. Paris, London, Uppsala, Berlin, and Bologna), the Imperial academic circle did not grow out of pre-existing academies, or groups of scholars, but had to be created ex-nihilo. Leibniz's recommendation to bring in foreign scholars was followed to the letter, with the first cohort of scholars hailing mainly from Protestant Germany. The Imperial Academy of Sciences was officially established in January 1724. Peter the Great died a year later, and therefore did not have time to see the actual opening of the Academy, which took place on 7 January 1726, in the presence of Catherine I, who succeeded her husband and took over his entire academy

\footnotetext{
${ }^{1}$ Maria Rosa Massa Esteve, "The circulation of scientific knowledge in Euler's first stage at Saint Petersburg Academy of Sciences", in The scientific dialogue linking America, Asia and Europe between the 12th and the $20^{\text {th }}$ Century. Theories and techniques travelling in space and time, by $\mathrm{F}$. D’Angelo, Naples, Associazione culturale Viaggiatori, 2018, 262-276.
} 
project. Of the twelve scholars present at the opening ceremony, eleven were German or Swiss $^{2}$. All three of the Swiss were mathematicians: Jakob Hermann, as well as the brothers Daniel and Nicolas Bernoulli, who died shortly afterwards. Of the eight German scientists attending the opening ceremony, including physicists Georg Bernhard Bilfinger and Friedrich Christoph Mayer, all were Protestants and seven had studied theology or had even held a religious position before moving to St. Petersburg. Seven other scholars joined the academy the same year, including the physicist Georg Wolfgang Krafft from Tübingen, who belonged to Bilfinger's sphere of influence, and the astronomer Joseph Nicolas Delisle, who was accompanied by his brother Louis de la Croyère, both from Paris and the only two Catholics at the Academy. The total number of academicians in 1727 was twenty, including Leonhard Euler, who arrived from Basel that year. Most of them were chosen on the recommendations of Christian Wolff, Leibniz's main successor, and his disciple Bilfinger, whose followers from the University of Tübingen alone accounted for a third of the scientists at the fledgling academy. The Wolffian group, led by Bilfinger, represented a large majority at the academy and was part of the Leibnizian opposition to Newton. The scholars from Basel, Daniel Bernoulli and Euler, for their part, along with Delisle, constituted the Newtonian group of the new Academy, even though Euler did not adhere to all of Newton's opinions. Jakob Hermann belonged to both movements.

It is in this setting that we must place the aurora borealis observations conducted at the Observatory under the direction of Delisle by Mayer, then Krafft, both disciples of Bilfinger, from 1726 onwards. The articles published by the scientists in the Academy's journal, the Commentarii Academiae scientiarum imperialis Petropolitanae, were immediately subjected

\footnotetext{
${ }^{2}$ Dimitri Bayuk, "Father Antoine Gaubil, S. J. (1689-1759) and his election to the Saint Petersburg Academy of Sciences", Conference on History of Mathematical Sciences: Portugal and East Asia V, 2018, p. 331-350.
} 
to religious censorship, which provoked the departure of Bilfinger and Hermann in $1730^{3}$. The opposition between Newtonians and Wolffians was manifested in the conflict of ideas between Daniel Bernoulli and Bilfinger, between 1726 and 1730. Bilfinger and Hermann quickly set up a think tank at the Academy around the natural philosophy of Leibniz and Wolff, defining as the primary substance, not Cartesian corpuscles or Newtonian atoms, but animated monads. Euler, at first reserved, because he was critical of Newton, took a position from 1736 onwards against the theory of the Leibniz monads, siding with the Newtonians in this instance. Thus, the conflict between Newtonians and Cartesians at the French Academy of Sciences found an equivalent in St. Petersburg, where the Leibnizians and Wolffians, whose doctrine was close to Cartesianism through its dualism and its mechanism ${ }^{4}$, opposed English empiricism for the same substantive reasons. The context of the opposition between Wolffians and Newtonians is of interest for the facts that we propose to relate here. In Part 2 we describe the historical and religious context in which the Northern Lights reappeared at the beginning of the 18th century, and the attempt at rational explanation offered by Christian Wolff to the citizens of Halle. Part 3 is devoted to the observations of the aurora borealis made at the St. Petersburg Observatory by Mayer, Krafft and Delisle, and to Mayer's early disinterest in the aurora system, which placed it much lower than it was observed, prompting him to neglect the observation of the aurora and the calculation of its height by a mathematical method of his own invention. By way of comparison, we show how Euler, taking into account the great height of the aurora, built an auroral system that corresponded more closely to observations. Part 4 presents a discussion of the philosophical context in

\footnotetext{
${ }^{3}$ Ronald Calinger, "Leonhard Euler: The First St. Petersburg Years (1727-1741)", Historia Mathematica, 23 (1996), 121-166.

${ }^{4}$ Sébastien Neveu, "L'a priori, l'a posteriori, le pur et le non pur chez Christian Wolff et ses maitres", Doctorate thesis in Philosophy presented at the Universite du Luxembourg, 2014.
} 
which observers of the aurora borealis in St. Petersburg evolved, and its possible influence on Mayer's choices. We finish the paper with a brief conclusion.

\section{Reappearance of the aurora borealis and observers from the Germanic world}

\subsection{Historical context of the sustained reappearance of the aurora borealis in 1716}

At the end of the Middle Ages, the people of North Germany were afraid of phenomena such as meteorites, and solar and lunar halos or rainbows ${ }^{5}$. The sky, considered to be eternal and unchanging by nature, had become a stage where frightening human and animal forms appeared, as diverse as they were inexplicable. Among the phenomena considered to herald disasters were the Northern Lights. It was in the Holy Roman Empire of Germany that printed texts predicting the occurrence of terrible evils and heralding an imminent end, often based on astrological predictions, were the most numerous. The apocalyptic fever that gripped Europe at the end of the 15 th century, and which was rapidly spread by the invention of printing, was the crucible in which the Lutheran reform, which split the Christian world, took place. The schism made reference to the texts of the Holy Scriptures predicting a limited duration for humanity and describing a violent apocalypse; such references greatly impressed the minds of ordinary people whose main concern was the struggle for daily survival in a context of great poverty. Luther's denunciation of the corruption of the Catholic Church, which equated the pope with the antichrist and attributed such anger to God that he himself would precipitate the world to its doom, further strengthened this sense of an imminent end; the miraculous signs imprinted in heaven could not fail to echo this impending doom in the popular imagination. In

\footnotetext{
${ }^{5}$ Wilfried Schröder, Changes in the interpretation of aurora and the example of the night of March 17, 1716, Acta Geod. Geoph. Hung. 40, 1 (2005), 105-112.
} 
the 17th century, the Thirty Years' War, which shook Europe until the middle of the century, contributed to the survival of old superstitions. Scientific knowledge did not penetrate into popular circles, and no awareness or questioning of the nature of disturbing celestial phenomena, which upset the purity of the vault of heaven, tempered the ancestral fears. The very possibility of discussing the reality of the scientific fact was denied to the people because of the total absence of transmission of the questioning itself. But, with the end of the Thirty Years' War in the middle of the 17th century, life gradually returned to normal. The idea that the end of the world had been averted gradually took over. Because of the low solar activity, no aurora borealis was observed during most of the 17th century, at least not since the aurora of 1621 observed by Pierre Gassendi. The phenomenon only resumed significantly in 1707, and then lastingly and repeatedly from 1716 onwards. Gassendi had already noted the great height of the phenomenon, deduced from its visibility over great distances, and the origin of the name "aurora borealis" was long attributed to him, although it was in fact coined by Galileo $^{6}$. Descartes had knowledge of this aurora, and in the Meteors (1637) ${ }^{7}$ identifies three possible origins for the phenomenon:

The first is that there are several clouds in the air small enough to be taken for as many soldiers, and which, falling one on top of the other, envelop enough exhalations to cause a lot of small flashes of lightning and to throw small fires, and perhaps also to make small noises because of which these soldiers seem to be fighting. The second, that there are also such clouds in the air, but that instead of falling on each other, they receive their light from the fires and flashes of some great storm, which occurs elsewhere so far away that it

\footnotetext{
${ }^{6}$ Robert H. Eather, Majestic lights: the Aurora in Science, History, and the Arts, American Geophysical Union, 1980.

${ }^{7}$ René Descartes, Les météores (1637), CEuvres de Descartes, Tome V, Texte established by Victor Cousin, Paris, F. G. Levrault, 1824.
} 
cannot be seen. And the third, that these clouds, or some other more northerly ones from which they receive their light, must be so high that the Sun's rays reach them ${ }^{8}$.

In other words, either the aurora borealis is a small thunderstorm, or it gets its light from a large distant storm that illuminates the clouds locally, or the source of light is the sun, which implies that the clouds are located at a very great height.

The lasting return of the aurora borealis after a century-long interruption (the period of low solar activity known as the "Little Ice Age") occurred spectacularly with the event of 17 March 1716. This event was observed throughout Europe, notably in London by Edmond Halley, who, in an article published in the Philosophical Transactions of $1717^{9}$, attributed its origin to the magnetic material circulating in the Earth's magnet, according to the theory established by Descartes. The aurora was also observed in France by Jean-Philippe Maraldi, who believed that it had a chemical origin through the ignition of the exhalations released by the Earth ${ }^{10}$. Two important observers of the event in the Germanic world were the astronomer and meteorologist Johann Friedrich Weidler at the University of Wittenberg and the philosopher Christian Wolff, a disciple of Gottfried Wilhelm Leibniz, in Halle. For Weidler,

\footnotetext{
${ }^{8}$ «La première est qu'il y ait en l'air plusieurs nues assez petites pour être prises pour autant de soldats, et qui, tombant l'une sur l'autre, enveloppent assez d'exhalaisons pour causer quantité de petits éclairs et jeter de petits feux, et peut-être aussi faire ouïr de petits bruits au moyen de quoi ces soldats semblent combattre. La seconde, qu'il y ait aussi en l'air de telles nues, mais qu'au lieu de tomber l'une sur l'autre, elles reçoivent leur lumière des feux et des éclairs de quelque grande tempête, qui se fasse ailleurs si loin de laquelle n'y puisse être aperçue. Et la troisième, que ces nues, ou quelques autres plus septentrionales de qui elles reçoivent leur lumière, soient si hautes que les rayons du soleil parviennent jusques à elles ».

${ }^{9}$ Edmond Halley, "An Account of the late Surprizing Appearance of the Lights seen in the Air, on the sixth of March last, with an Attempt to explain the Principal Phænomena thereof', Philosophical Transactions of the Royal Society of London, 29 (1717), 406-428.

${ }^{10}$ Bernard le Bovier de Fontenelle, Sur une lumière horizontale, HARS 1717 (1719), 3-5.
} 
the cause of the aurora is to be found in the sulphur particles rising from the volcanoes, which are supposed to be numerous in the far north, and which would ignite at high altitudes ${ }^{11}$. Wolff, on the other hand, gives the phenomenon a meteorological origin, close to Descartes' first explanation, namely that the aurora is the manifestation of an "imperfect thunderstorm"12, during which the exhalations are not made subtle enough by the heat to rise into the atmosphere, and fall back before the thunder has had time to burst. He situates this small thunderstorm quite low in the atmosphere, at an altitude of less than $3000 \mathrm{~m}$.

\subsection{Christian Wolff's lecture}

In the week following the event, Wolff gave a lecture to the general public to present his version of the event, explicitly discounting any suggestion that it might have been a divine message. Here is how he expresses himself on the subject:

When last Tuesday after darkness on the 17th of March of the present year 1716 in the evening an unusual light appeared to us in Halle towards the North in the sky (which, as we learned soon afterwards, was also observed at many other places lying on parallels close to that of Halle) and many who are inexperienced in their knowledge of nature felt great consternation; therefore many different people asked my opinion about this strange phenomenon and especially wanted to know if it can be explained anyhow with some basis. As I felt that in this case the people had some confidence in me and considered me

\footnotetext{
${ }^{11}$ Per Pippin Aspaas, "The Auroral Zone versus the Zone of Learning: A Brief History of Early Modern Theories on the Aurora Borealis, Geophysics, Early Modern History, History of Science”, in A Multidisciplinary Approach to the Long History of Northern Travel Writing, Marie-Therese Federhofer, and Per Pippin Aspaas (eds), Hannover: Wehrhahn Verlag, 2013, p. 113-135.

${ }^{12}$ Christian Wolff, Gedanken über das ungewöhnliche Phøenomenon, Lectione Publica, Auf der Universität zu Halle erhöffnet, Halle, 1716.
} 
as appointed to explain the book of Nature; I decided to expound my ideas about it at a Lectione publica on the 24th March, which a large audience attended... ${ }^{13}$

Christian Wolff was born in 1679 in Breslau, a town in Silesia, which became Wrocław in present-day Poland. As a brewer's son destined for theology, he was particularly precocious and took an interest in science as part of his primary and secondary education at the Breslau Gymnasium. Witnessing the endless theological disputes between Catholics and Lutherans at his grammar school, Wolff was very early on determined to replace theology with mathematical truth as the basis for unquestionable deductive reasoning:

But, because here I lived among the Catholics and, since childhood, I observed the Lutherans' disputes with the Catholics, I noticed in this respect that everyone thought they were right; I couldn't get the thought out of my head that it was not possible to show the truth in theology as distinctly as when it is removed from contradiction. As now I heard afterwards that mathematicians proved their propositions so certainly, that each of them had to be recognized as true, I wanted to learn mathematics for the method, in order to strive to bring theology to an unquestionable certainty. ${ }^{14}$

It was first and foremost as a first step towards acquiring a rigorous method of exercising thought, far from dogmatic theological discourse, and not as an end in itself, that Wolff first envisaged the study of mathematics. For him, the authority of scientific discourse, of a causal and demonstrative nature ("philosophical" knowledge), must be placed above that of religious discourse, which approaches its object in a factual and descriptive manner ("historical" knowledge). Once this pre-eminence of philosophy over theology has been established, all of

\footnotetext{
${ }^{13}$ Op. cit. in n.5.

${ }^{14}$ Op. cit. in n.4.
} 
Wolff's work is marked by the desire to articulate, in a philosophical approach to the world, the two great axes of reason and experience; Wolff's approach essentially focuses on the "knowledge of the world", whereas his Germanic predecessors placed the "revealed knowledge of God" at the centre. At the time this articulation was a bone of contention between the two rival schools of empiricism on the one hand, embodied by Locke in England, which favoured concrete sensitive experience, and rationalism on the other, embodied by Descartes in France, which favoured deductive demonstration. This synthesis, this "marriage of experience and reason", as intimate as possible, was for Wolff the most important operation of philosophy, being useful for establishing the greatest number of certainties, and for advancing "prodigiously" in the sciences. He sees in the common observation of nature the source of all possible knowledge, and in experimentation the first positive step of rigorous science, the human mind being active and directive. The rational experience of the sensible world is thus the intermediary between pure sensation and pure demonstration, which achieves the marriage of experience and reason. The latter plays an essential role. For Wolff, the sensible experience concerns individual objects, and cannot explain the why of things, which has to do with the relations between objects, inaccessible through experience alone: "A man who is ignorant of Philosophy can indeed learn from the experience of many possible things, but he cannot give reason for their possibility. Experience tells us that it can rain but does not tell us why it rains or how it rains".

Wolff's Elements of Aerometry, published in $1709^{15}$, offers an interesting example of the Wolffian approach, and constitutes one of the first treatises on meteorology, in the sense of a branch of physics based on observations of atmospheric parameters. Meteorological

${ }^{15}$ Abraham Wolf, A History of Science Technology and Philosophy in the 18th Century, London, George Allen \& Unwin Ltd, 1962. 
observations were only just beginning to be systematized in astronomical observatories at that time and it would take more than half a century for all the material thus collected to be analyzed scientifically, for example by Louis $\operatorname{Cotte}^{16}$, despite the difficulties inherent in the physical formalization of meteorology. Wolff's treatise, in accordance with the philosopher's doctrine, is mathematical in form, relying on "definitions" of terms, such as aerometry, "scholies" commenting on the meaning of words, "axioms", such as the fact that heavy bodies press perpendicularly downwards on the bodies below them, "theorems", such as BoyleMariotte's law, or "problems", such as that of the construction of an air pump. The treatise goes back to some famous experiments carried out in the previous century by Galileo, Torricelli, and Boyle and takes stock of the question of the height of the atmosphere, determined by the duration of the twilight, or by the air pressure using the barometric law, and makes statements regarding purely meteorological issues. Wolff attributes the winds to sudden expansions or compressions of the air caused by fluctuations in the heat deposited locally by the Sun. He gives a brief description of the measuring instruments, with an emphasis on the hygrometer and anemometer, which he describes in more detail. In the first case, he describes how the length of a hemp rope varies with the degree of humidity; the rope, from which a weight is suspended, is passed through a pulley and measurements are indicated by a pointer attached to the latter. In the second case, the wind turns a small wind turbine which drives a wheel by means of a worm. The wheel is fitted with a radial arm carrying a weight at its end, oriented vertically downwards at rest. The torque exerted by the wind on the wheel causes it to rotate until the weight exerts exactly the opposite torque, the angle of equilibrium rotation of the wheel then providing the wind speed. The author also describes an air pump system, giving the mathematical expression of the residual amount of air in the

\footnotetext{
${ }^{16}$ Louis Cotte, Traité de météorologie, Paris, Imprimerie Royale, 1774.
} 
receiver, i.e., at the $\mathrm{n}^{\text {th }}$ pump stroke, the $\mathrm{n}^{\text {th }}$ power of the receiver capacity relative to the $\mathrm{n}^{\text {th }}$ power of the capacity of the receiver and the cylinder (where the air is pumped) together. This treatise, which is not very innovative in itself, is a condensed version of Wolff's philosophy, where all the elements which, according to him, constitute the strength of the scientific approach are brought together - mathematical reasoning, physical experimentation - both in terms of instrument design and the results of observation, and it attempts to provide a general explanation of the causes of phenomena, such as wind.

It was precisely this approach that guided him in the lecture he gave in Halle on $24^{\text {th }}$ of March 1716 on the subject of the Northern Lights. He was then professor of mathematics and physics at the University of Halle, a chair he had obtained ten years earlier thanks to Leibniz, one of the great influences on his thinking, along with Galileo and Descartes. In the meantime, Wolff had extended the scope of his teaching to include philosophy, and had met with great success among his students. He also extended his approach to the truths of the faith, a claim that in 1723 earned him an injunction to leave Prussia on pain of death. He spent seventeen years in Marburg, before being recalled to his post as professor in Halle by Frederick the Great in 1740; he subsequently became vice-chancellor of the university. In the public note accompanying the announcement of the lecture, Wolff wrote that he wanted to discuss the following points ${ }^{17}$ :

1. Whether our phenomenon is something special, or whether it has been previously seen at other places and whether it has been observed by diligent observers;

2. Whether this belongs to the group of meteor(ological events)s as they are called by naturalists, and if this question is answered in the affirmative, which class of meteors should it be included in;

\footnotetext{
${ }^{17}$ Op. cit. in n.5.
} 
3. Thirdly, I promise to investigate briefly the causes by which these curious phenomena in the air originate and

4. I want to briefly touch on the consequences, and also the significance of such phenomena.

Wolff, in his lecture, addressed all of these questions and affirmed that this optical phenomenon does not in any way express a judgement of God, but is a natural behaviour of the Earth's atmosphere. This event was a turning point. For the first time, responding to what he considered his duty, a professor had opened the "book of nature" to deliver a rational explanation, free of theological bias, to an audience of interested lay people. The conference participants had all witnessed the aurora borealis of the previous week, and the keys Wolff offered to explain it, far from the eternal truths professed by the church, opened their minds. Heaven was no longer the immutable and perfect sphere that was disturbed by phenomena, deemed alarming because they broke this immutability, but was the atmosphere of the Earth, the seat of natural phenomena that needed to be understood.

\section{Further developments in the study of the Northern Lights in the German-Russian world}

\subsection{Wolff's Disciples at the Imperial Academy of Sciences in St. Petersburg}

Joseph Nicolas Delisle, in the Mémoires pour servir à l'histoire et au progrès de l'astronomie, de la géographie et de la physique, which was printed in St. Petersburg in $1738^{18}$, describes his own contribution to the observation of the aurora borealis in the period from September

\footnotetext{
${ }^{18}$ Joseph-Nicolas Delisle, Mémoires pour servir à l'histoire et au progrès de l'astronomie, de la géographie et de la physique, St. Petersbourg, Imprimerie de l'Académie des Sciences, 1738.
} 
1734 to the end of 1736 . Before him, two academics took turns in this observation task, first Friedrich Christoph Mayer, from October 1726 until his death at the end of 1729, and then Georg Wolfgang Krafft, who took over after Mayer's death, and who was also tasked with making daily weather observations. Both Mayer and Krafft were pupils of the philosopher and mathematician Georg Bernhard Bilfinger. Coming from a family of theological academics, Bilfinger was interested from an early age in mathematics, which he mastered by reading Wolff and Leibniz. After holding several religious positions, he became associate professor of philosophy at the University of Halle in 1721. His treatise linking philosophy and theology, essentially based on the Wolffian doctrine, was a great success. The accusation of atheism directed against Wolff in 1723 also reflected on Bilfinger; he was rejected by his peers and students deserted his classes. He was dismissed as a teacher in 1724. It was this event that led him, with Wolff's help, to apply for a position as professor of physics at the new Imperial Academy of Sciences in St. Petersburg, which he joined when it was inaugurated at the end of 1725 .

Friedrich Christoph Mayer, born in 1697, came to St. Petersburg from Tübingen, where he was Bilfinger's student in the disciplines of mathematics, theology and philosophy, and served three years as curate after his doctorate. Very little biographical information is available about him. He probably stayed in St. Petersburg as a visitor in 1725 , before being appointed Professor Extraordinary, i.e. without an explicitly defined discipline, the following year. He is recognized in the new academy as a specialist in "mathesis", i.e. "the foundation of knowledge", a rationalist project inherited from Descartes and Leibniz based on the fact that it should be possible to understand the universe on the basis of a small number of simple laws, 
the universal order thus proving to be accessible to reason ${ }^{19}$. During the four years he spent at the Academy, Mayer, who worked with Delisle at the Observatory, notably composed a calendar, the first and only one for a long time not to include astrological elements ${ }^{20}$. It is also known that from the time of Leonhard Euler's arrival in 1727, he helped the Basel mathematician with various problems of celestial mechanics applied to the determination of the sun's orbit, the movement of the planets and the calculation of lunar eclipses. In addition, he worked with two other Basel mathematicians, Jakob Hermann and Daniel Bernoulli, on a theory of the moon based on Delisle's extensive programme of astronomical observation, which included the occultations of stars and planets by the moon, as well as lunar and solar eclipses. This work gave rise to several of Mayer's publications in the first volumes of the Commentarii. One of Mayer's most outstanding subjects of study is the observation of and theory regarding the aurora borealis. Delisle states that Mayer observed many auroras during the first year of his stay in Russia as part of his meteorological observation work, and that in 1728 he published in the first volume of the Commentarii a collection of his observations, accompanied by "his thoughts on the cause of this phenomenon, \& the first foundations of his system, which he strove to perfect until his death three years later"21. He is rather negative about Mayer's observational skills, judging that the latter did not take the trouble to write down the details of his auroral observations, often indicating only the day. We shall return to Mayer's system, as well as to his mathematical method - not mentioned by Delisle, although it

19 David Rabouin, Mathesis Universalis: L'idée de «mathématique universelle » d'Aristote à Descartes, Presses Universitaires de France, 2009.

${ }^{20}$ René Sigrist, Alexander Moutchnik, «Entre Ciel et Terre: les fonctions de l'astronomie sans la Russie du $18^{\text {ème }}$ siècle », Almagest, International Journal for the History of Scientific Ideas 6/2 (2015), 85-124.

21 “ses pensées sur la cause de ce phenomene, \& les premiers fondemens de son sistême qu'il a tâché de perfectionner jusqu'à sa mort arrivée trois années après”. 
was published in the same article - which he devised to estimate the height of the auroral arc without measuring parallax, i.e. from a single place of observation.

Georg Wolfgang Krafft took over the meteorological monitoring after Mayer's death in 1729, a task that included observation of the aurora borealis. He was the son of a pastor and studied theology, mathematics and natural history under Bilfinger and other masters, being in charge of a cabinet of natural curiosities, among other things. In 1728, Krafft was awarded the degree of Master of Arts at the University of Tübingen. Bilfinger, already in St. Petersburg at the time, obtained a position for him at the new Imperial Academy of Sciences, which he accepted. Krafft was asked to teach mathematics at the Academy's grammar school, pending a position as a mathematics teacher, which came five years later. Krafft, like Mayer, belonged to the circle of mathematicians at the Academy, composed of the Basel mathematicians Bernoulli, Hermann and Euler, and Christian Goldbach from Königsberg, who were asked by Delisle to process his extensive astronomical observation data ${ }^{22}$. Concerning the observation of the aurora borealis, Delisle seems more satisfied with Krafft's work than Mayer's. He indicates that Krafft continued Mayer's meteorological observations and that he "also marked most of the days on which these lights in the sky appeared, \& did not omit the main circumstances of the most remarkable ones" ${ }^{23}$. It is also known that Krafft organized a group of amateur observers in St. Petersburg to observe the Northern Lights and that on two

\footnotetext{
${ }^{22}$ The names, subjects, and places of origin are given in Ronald S. Calinger, Leonhard Euler: Mathematical Genius in the Enlightenment (Princeton: Princeton University Press, first paperback edition, 2019), 48 - 53.

${ }^{23}$ «a aussi marqué la plupart des jours auxquels il a paru de ces lumieres au ciel, \& n'a pas omis les principales circonstances de celles qui étoient les plus remarquables ».
} 
occasions he tried to measure the height of the phenomenon, which he found to be close to $1,000 \mathrm{~km}$ in both instances ${ }^{24}$, a very high value in this case.

\subsection{Mayer's rejection of aurora borealis observations}

Mayer and Krafft were directly descended from the Wolffian school through their Bilfinger education in Tübingen. They both studied theology, but they also turned to mathematics to give their work as scientists as much rigour as possible. In St. Petersburg, one after the other, they were responsible for meteorological monitoring, which included the observation of the aurora borealis, a phenomenon considered to be of a meteorological nature (a "meteor"), in keeping with the Cartesian heritage. Mayer presented his theory of the aurora borealis as early as 1726 in an article written in Latin and published in the Commentarii of $1728^{25}$. This article is transcribed in full in its English translation in Appendix 1. In it, he first describes what he considers to be the two most commonly observed types of aurora borealis:

The first kind is common and more frequent in our regions: shaped like an arc, it is located in the north and emits rays that look like light beams upwards and shines with a quiet light. The second kind, which is rarer, is turned towards the sky, of which it occupies every region, and is fragmented into different parts wherein beams, that are either very short or non-existent, are most commonly fixed. The splendour of this kind of polar lights, as it is often thought, is that it undulates or trembles..

\footnotetext{
${ }^{24}$ Op. cit. in n.6.

${ }^{25}$ Friedrich Christoph Mayer, "de Luce Boreali”, Commentarii Academiae scientiarum imperialis Petropolitanae, 1726 (1728), 351-367.
} 
Concerning the first type, he sets out its characteristics in terms of the geometry of the arcs, their variability (displacement, division/melting), the properties of the region of the sky located under the arc (black, but transparent to starlight, except at the level of the dark inner margin of the arc), the existence of parallel and intermittent vertical beams, animated by horizontal displacements, rising towards the top of the arc, and sometimes exceeding it, the appearance of clouds higher than ordinary clouds. Concerning the second type, he describes it as a general burning of the sky, with small bright clouds scattered throughout the sky, sometimes extinguishing, sometimes igniting, and sometimes projecting beams of light, which he likens to the phenomenon of lightning. He also notes that it is often accompanied, preceded, or followed, by auroras of the first type. He then highlights the properties common to both types of aurora, in particular an appearance between the autumn and spring equinoxes. He concludes that these two kinds differ in appearance only. Most of their characteristics are in fact shared (cf. §VI in Appendix 1) and if "we might think that some are particular to one kind of polar lights, this is, as I shall explain later, only because of the diversity of the places, a diversity which is itself observed".

He goes on to explain that (i) light either comes to us in a direct line from the brilliant matter of the aurora, (ii) or is due to the refraction of light from a source located behind the region where the auroral matter is present, (iii) or is produced "by the reflection of rays emitted by a luminous matter which is not present at the place where we see the beams". He rejects the first hypothesis because, in this case, due to the roundness of the Earth, the plane of a distant aurora deviates from the local vertical to the observer, inducing, through an effect of perspective, a geometric distortion of the auroral structures. As a result observers in different places distant from the same aurora, or an observer of different auroras occurring over time in different places, should never see the same thing; he believes this is contradicted by the 
observation, but provides no further explanation. He rejects the refractive hypothesis, for reasons that are not very explicit, and comes to the conclusion that only the hypothesis of reflection of light is tenable, a hypothesis that he then endeavours to prove. First of all, he assimilates auroral matter to cloud matter on the basis of the fact that the dark lower edge of the arc of light "has to be regarded as a cloud", all the more so since the aurora often displays small pulsating luminous clouds. He thus concludes: "it is obvious that this matter has all the characteristics of clouds and thus occupies the same position as them and is the same distance from the Earth". He also invokes another reason: according to him, the arc can be explained by a ring of auroral matter situated at a certain altitude, at a certain latitude, and extending around the Earth along the corresponding parallel (a representation that forms the basis of his method for estimating the height of the aurora). In this case, the auroral material, like that of extended clouds seen on the horizon, has a sharp lower edge, again showing, according to Mayer, the resemblance between auroral and cloud material. This analogy with clouds allows him to suggest that the two types of aurora are manifestations of the same phenomenon, the distinction only arising from the place from which the phenomenon is observed: "the matter of this light is scattered and disjointed in the small luminous clouds; but the first kind of light appears continuous $[\ldots]$ and more radiant $[\ldots]$ because in this case the matter is seen from a distance and in an oblique way". The clouds, when seen up close, appear individualized in their diversity of shapes, and when seen from afar, near the horizon, appear as a uniform layer of vapour with a well-defined lower edge. In the same way, the second type of aurora (a general blazing of the sky) corresponds to an aurora seen up close, while the first type (the arc and pulsating beams) corresponds to an aurora seen from afar.

It remains to be explained where the beams come from, these vertical jets and columns rising towards the top of the arc. Here Mayer summons his observation of a distant fire from his 
window on a snowy evening, when he sees a column of light rising into the sky as the light of the fire is reflected back to him by the snowflakes. He also evokes the reflection of a star in calm water, which gives rise to a column due to the irregularities generated by the agitation of the liquid surface: "the moon or any luminous star irradiating the surface of a quiet body of water sends back to the eye a beam similar to the one that I have described". And he forwards the hypothesis that this is the origin of the jets: "I assert that the beams of polar light are issued from the reflection of the light that is present in the small luminous clouds [...] while these small clouds project beams upwards onto the flat surface of the very tenuous vapours that overlook them, through which light is subsequently reflected in the form of beams". Because, according to Mayer, "the flat, inferior part of the clouds, is undulating, flat and it results from the smooth water or ice particles". It is this lower surface that reflects the light from the small clouds towards the observer, generating the columns of reflected light that make up the observed beams. The physical cause of the light emitted by the auroral matter constituting the small clouds remains to be defined and this cause is far from obvious, or at least, according to Mayer, much less obvious than the optical theory previously developed: "The explanations I have provided up to now have, I suppose, a degree of certitude; however, there exist other phenomena the explanations for which I do not promise to be equally certain of". Mayer states the following principle, of which he says he is not entirely certain, but presents nonetheless "for posterity's benefit": during the summer, "the flammable exhalations [sulphur, nitre, salts], with the aid of heat, mingle and merge with the watery vapours and are then separated from them when the cold arrives, at the moment when the watery vapours gather faster than the flammable exhalations". He proposes a cycle of ignition-extinction where the heat generated by the ignition causes the exhalations to mix with the vapours, which then separate again when the air cools down, re-concentrating the exhalations and provoking a new ignition: 
gradually the flammable exhalations leave these small clouds and gather above them $[\ldots]$; once a sufficient amount of these exhalations has accumulated, it produces a flame and catches fire $[\ldots]$; a new accumulation is formed by this ignition, it catches fire and the story repeats itself as many times as possible. I think this fits admirably with what the very famous professor Wolff said about them, when he called the matter of lightning the matter of the polar lights.

He therefore explicitly refers to Wolff's theory of the "imperfect storm". Note that the same theory is found in the work of another of Wolff's disciples, Johann Christian Heuson, who provides a similar interpretation of the aurora borealis of February and March 1721, and November $1729^{26}$. For Mayer, the substance of the aurora borealis is that of the clouds, and the auroral light is similar to that of a small flash of lightning, as Wolff advocated. The specificity of Mayer's system is that the light produced by the auroral matter is reflected by high clouds (or "vapours"), thus explaining the formation of luminous columns. Mayer's explanation reflects the fact that the Northern Lights, according to him, only occur between the autumn and spring equinoxes, i.e. during the autumn and winter. During this period, the lower air cools, causing the warmer air inherited from the summer to rise, and it is at the top of the cold layer that the aurora borealis is born through the mechanism described.

The hypothesis of the ignition of exhalations was forwarded quite frequently at the time. Halley offers a similar explanation in his 1717 article on the aurora borealis which took place in the previous year, only to immediately dismiss it as unrealistic and propose instead the effect of magnetic matter. Weidler, as we have seen, invokes the ignition of the sulphurous

\footnotetext{
${ }^{26}$ Kristian Schlegel, Sam Silvermann, "Johann Christian Heuson, a little-known auroral scholar of the early $18^{\text {th }}$ century”, Hist. Geo Space Sci., 2 (2011), 89-95.
} 
matter thrown up by volcanoes. Halley, writing in 1719 , uses the hypothesis of ignition to explain the formation of "flying fires" (entry of meteoroids into the atmosphere) ${ }^{27}$ and, generally speaking, there is a whole slew of scientists, including Pieter Van Musschenbroek, for example, who explain all meteors (atmospheric lightning, fire globes and shooting stars, aurora borealis) as having the same chemical origin, linked to the ignition of sulphurous matter released by the Earth into the atmosphere ${ }^{28}$. In France, throughout the decade following the aurora of 1716 (after which aurora appeared on a regular basis), Maraldi and Fontenelle gradually developed a hypothesis based on ignition ${ }^{29}$. This theory was eventually dethroned in 1731 at the Academy of Sciences by the Mairan system ${ }^{30}$, which invoked the precipitation of solar matter at great heights in the atmosphere.

Furthermore, on the strength of his knowledge of mathematics, at the end of his article Mayer proposes a trigonometric method for estimating the height of the auroral arc from a single point of observation. As we have seen, he represents auroral matter by a circular ring centred on the axis of rotation of the Earth; he places this ring at a certain altitude, and parallel to and vertically above a certain latitude. The latitude and altitude of the ring are the two unknowns of the problem. He establishes a trigonometric formula that allows, from the angular height of the top of the arc and its angular width on the horizon (two observable quantities), to determine the height of the ring above the ground, and its latitude. This method met with great

\footnotetext{
${ }^{27}$ Edmond Halley, "An Account of the Extraordinary METEOR Seen all over England, on the $19^{\text {th }}$ of March 1718/19. With a Demonstration of the uncommon Height thereof", Philosophical Transactions of the Royal Society of London, 30 (1719), 978-990.

${ }^{28}$ Pieter van Musschenbroek, Des météores ignés, Essai de Physique, Leiden, Samuel Luchtman, 1739, 813-847.

${ }^{29}$ Bernard le Bovier de Fontenelle, « Sur une lumière horizontale », HARS 1717 (1719), 3-5.

${ }^{30}$ Jean-Jacques Dortous de Mairan, Traité physique et historique de l'aurore boréale (1731), Paris Imprimerie Royale, 1733.
} 
success in the community of astronomers and mathematicians of the time. The result is presented in volume 5 of the Commentarii of the Imperial Academy published in 1735, five years after Mayer's death. Pierre Louis Moreau de Maupertuis, an ardent defender of Newton's theory of universal attraction, who a few years later led an expedition to Lapland to measure the shape of the Earth, gave a demonstration of Mayer's method in the Mémoires de l'Académie des Sciences in $1731^{31}$. Krafft presented a simplified version using logarithms in Volume 9 of the Commentarii published in 1737. The Reverend Father Roger Joseph Boscovich, in his treatise on the aurora borealis published in 1738, while pursuing theological studies in Rome, similarly takes up Mayer's problem, for which he gives his own demonstration $^{32}$. He does not share Mayer's opinion on the origin of the phenomenon, agreeing instead with the concept described by Mairan.

As Mairan remarks in his Enlightenment XIII of the second edition of his treatise ${ }^{33}$, and as Mayer himself noted in his second dissertation ${ }^{34}$, the hypothesis of the circular shape of the ring, and its concentricity with the pole (or the Earth's axis), is in practice rarely verified, which is why Mairan favours the parallax method, which requires two distant observers simultaneously observing the same structure. Here is what he has to say about it:

\footnotetext{
${ }^{31}$ Pierre Louis Moreau de Maupertuis, « Problème astronomique », HARS 1731 (1764), 464-465.

${ }^{32}$ Inga Lisac, Ivica Martinovic, Vladis Vujnovic, Ruder Boskovic's Insights on Polar light, Published in the Treatise De aurora boreali in 1738, The International Scientific Symposium, Philosophy of Ruder Josip Boskovic, Faculty of Philosophy of the Society of Jesus, Zagreb, Croatia, November 4, 2011.

${ }^{33}$ Jean-Jacques Dortous de Mairan, Traité physique et historique de l'aurore boréale, Seconde Édition, Paris, Imprimerie Royale, 1754.

${ }^{34}$ Friedrich Christoph Mayer, "de Luce Boreali”, Commentarii Academiae scientiarum imperialis Petropolitanae, 1729 (1735), 121-129.
} 
His first Memoir, "De Luce Boreali", presented in 1726 at the Imperial Academy of St. Petersburg, $[\ldots]$ contains, as we have said, only the simple exposition of his Problem or Method, \& the Analytical Formula which results from it. But as early as 1728, he had presented to the same Academy both the geometrical construction \& the demonstration, but it was not until 1735 that they were published, along with the remarks that the observation of a large number of Aurora Borealis had provided him in the meantime. It is in this second Memoir that he presents the corrections that must be made to the first as a consequence of these remarks, $\&$ the restrictions that must be placed on his entire theory. [...] However, despite these simple limitations, which are reduced to regarding only as ordinary $\&$ more frequent that which he had treated as constant $\&$ absolute, despite these appearances of the Aurora Borealis, which had become so common in St. Petersburg, that the people were no longer astonished as they had been in the past, despite, I say, such a favourable position \& time, he ends his Memoir by admitting to us that he had not yet been able to find any instance of these Phenomena wherein the observations could be explained by his Rule ${ }^{35}$.

Mairan estimates the height of the auroral arc by applying Mayer's method in cases where the conditions for applying this method seem to be best verified. He thus finds, for the auroral arc

\footnotetext{
35 «Son premier Mémoire, «de Luce Boreali », lû en 1726 à l'Académie Impériale de Pétersbourg, [...] ne contient, comme nous l'avons dit, que la simple exposition de son Problème ou de sa Méthode, \& la Formule analytique qui en résulte. Mais dès 1728, il en donna à la même Académie \& la construction géométrique \& la démonstration, qui ne parurent cependant qu'en 1735, avec les remarques qu'un grand nombre d'Aurores Boréales qu'il avait observées depuis avoient pu lui fournir. C'est dans ce second Mémoire qu'il nous annonce les corrections qu'il faut faire au premier en conséquence de ces remarques, \& les restrictions qu'on doit apporter à toute sa théorie. [...] Cependant malgré ces simples limitations qui se réduisent à ne regarder que comme ordinaire \& plus fréquent ce qu'il avait traité de constant \& d'absolu, malgré ces apparitions de l'Aurore Boréale, devenues si communes à Pétersbourg, que le peuple n'en était plus étonné comme autrefois, malgré, dis-je, une position \& un temps si favorables, il termine son Mémoire par nous avouer, qu'il n'avoit pû trouver encore aucun de ces Phénomènes dont il pût appliquer les observations à sa Règle ».
} 
of 1621 (observed by Gassendi), well centred on the geographical north and presenting a halfamplitude of $59.5^{\circ}$ and a height of $40.5^{\circ}$, and using Krafft's logarithmic formula, a height of 160 leagues $(770 \mathrm{~km})$. In the case of the aurora of 3 February 1750 , which was particularly clear and well-defined, and observed from various places in Europe, the height deduced by Mayer's method is 134 leagues $(650 \mathrm{~km})$, almost identical to that obtained by the parallax method. He also cites three observations of auroras made in 1730, two in St. Petersburg and one in Geneva, to which Krafft applied Mayer's method, obtaining a height of 170 leagues $(820 \mathrm{~km})$ for one of them, but only about 50 leagues $(250 \mathrm{~km})$ for the other two. Mairan ends his explanation with a table in which he reports the altitudes of about fifty auroras, estimated either by the parallax method or by Mayer's method when the conditions allow it to be applied, deducing an average aurora altitude of 175 leagues $(850 \mathrm{~km})$.

Mairan then tries to understand why Mayer himself so rarely applied his method to his own aurora observations. The hypothesis he forwards to explain Mayer's lack of conviction in using his own method is interesting:

He believed along with an illustrious Philosopher [most probably Wolff], that the matter of the Aurora Borealis was little more than an indigestible heap of that which produces Thunderbolts \& Lightning [...] \& consequently he did not make the Arc of Lightning rise above the region of the clouds [...]. What could he think of such a principle, when his rule yielded a hundred times that distance, \& sometimes even more! However, his rule was good, it was proven, he was a skillful calculator; it was therefore necessary to question the observations which he could not fail to find faulty, \& infinitely more faulty than they were, since they resulted in such a huge alleged error. This, if I am not mistaken, is the answer to the mystery, \& why Mr. Mayer probably neglected to report to us attempts which must have seemed so defective to him. In the same or the following year he 
presents some other Memoirs in which there is no longer any mention of the Boreal Light, \& he died on December 5, $1729^{36}$.

It probably explains Delisle's surprising finding about Mayer's observations of the Northern Lights:

But with regard to the particular observations he made on each Aurora borealis, it seems that he was content to fill his imagination with them, without putting them in writing, since only very few of the circumstances of his meteorological observations were found in the collection of his observations ${ }^{37}$.

This lack of eagerness on Mayer's part to describe observed aurora phenomenon, noted by Delisle, corroborates Mairan's explanation that Mayer did not trust aurora observations. There is no doubt that he was a good enough mathematician to judge that his method of estimating the height was accurate, but the result of the observation contradicted the theory he had

\footnotetext{
${ }^{36}$ " Il croyoit avec un illustre Philosophe [très probablement Wolff], que la matière de l'Aurore Boréale n'étoit guère autre chose qu'un amas indigeste de celle qui produit la Foudre \& les Eclairs [...] \& en conséquence il n'en faisoit pas monter l'Arc lumineux au dessus de la région des nuées [...]. Que pouvoit-il donc penser d'après un tel principe, lorsque sa règle le renvoyoit au centuple de cette distance, \& quelquefois au-delà ! Cependant sa règle étoit bonne, elle étoit démontrée, il étoit habile calculateur; il falloit donc s'en prendre aux observations qu'il ne pouvoit manquer de trouver fautives, $\&$ infiniment plus fautives qu'elles n'étoient, puisqu'il en résultoit une prétendue erreur si énorme. Voilà, si je ne me trompe, le dénouement de la difficulté, \& pourquoi M. Maier négligea sans doute de nous rapporter des tentatives qui devoient lui paroître si défectueuses. Il donna la même année ou la suivante quelques autres Mémoires dans lesquels il n'est plus question de la Lumière Boréale, \& il mourut le 5 Décembre 1729 ».

37 «Mais à l'égard des observations particulieres qu'il a faites sur chaque Aurore boreale, il y a apparence qu'il s'est contenté de s'en remplir l'imagination, sans les mettre par écrit, puisque l'on n'a trouvé dans le recueil de ses observations meteorologiques, que très peu de circonstances de ces observations », Op. cit. in n.18.
} 
developed. According to this theory, the height of the aurora could not exceed the height of the highest vapour layers, which were supposed to reflect the light of the small clouds of auroral matter towards the observer, a height one hundred times lower than the value arrived at using Mayer's mathematical model. On reading Mayer's article, one is struck by the theoretical and deductive nature of the thought path which leads him to his system, based only on a few general observational characteristics of the aurora: the presence of an arc materializing the ring of auroral matter, the lower edge of which, cut off, evokes that of a distant cloud layer seen on the horizon, the existence of vertical columns reminiscent of the reflection of the moon on a body of water, evoking the idea of a discrete light source (a small cloud) reflecting on a slightly agitated surface (the lower surface of a layer of vapours). Mayer does not seem to see the contradictions inherent in his approach, the first and principal one of which, namely the great height of the aurora, ruins his system. His argument for rejecting the hypothesis that the light of the aurora is seen in a direct line (without the interposition of a reflecting obstacle) is based on the (correct) identification of geometric distortions in the shape of the aurora due to the roundness of the Earth which can only occur if, precisely, the aurora is located at a very high altitude (as logically shown by the result of his mathematical model), far above the clouds.

It is instructive, at this stage, to compare Mayer's case with that of Euler, another mathematician, who also developed a system of the aurora borealis, a system precisely based on the observation of the very great height of the aurora.

\subsection{Euler's re-evaluation of the aurora borealis system to bring it into line with experience}


In Basel, where he wrote his thesis on the comparison between Cartesian and Newtonian conceptions, Euler was noticed as an outstanding mathematician by his professor Jean Bernoulli, father of Daniel Bernoulli. The latter, who was one of the first scholars to enter the Academy of St. Petersburg, addressed a letter to Euler in 1726 in which he wrote: "Sir, a few months ago I wrote to you by order of our President, Mr. Blumentrost, and invited you in his name to come and take a place as a pupil in our Academy... You are awaited with great impatience; come therefore as soon as possible..." ${ }^{38}$. Euler left Basel on 5 April 1727, passing through Marburg on his way to see Christian Wolff, and arrived in St. Petersburg on 24 May 1727. From his early days at the Academy, under the direction of Delisle, he became closely associated with the work of the Observatory in the field of astronomy, but also in geography. It was probably at the Observatory, where he himself was able to observe many auroras, that his interest in this phenomenon was born, an interest that would lead him, some twenty years later, to publish his own theory ${ }^{39}$. It is known that in 1729 he studied various conjectures on the nature of the aurora borealis ${ }^{40}$, and it is undoubtedly this reflection, shared with his colleagues Mayer and Krafft, who only interacted with each other for one year between Krafft's arrival at the end of 1728 and Mayer's death at the end of 1729, that led him to his theory of the aurora published in 1746, five years after his departure from St. Petersburg for Berlin.

\footnotetext{
${ }^{38}$ Op. cit. in n.1.

${ }^{39}$ Leonhard Euler, «Recherches Physiques sur la cause de la queue des comètes, de la lumière boréale, et de la lumière zodiacale », Histoire de l'Académie Royale des Sciences et des Belles-Lettres de Berlin (1746), 117-140.

${ }^{40}$ Op. cit. in n.1.
} 
In the intervening period, Mairan had published his famous model involving precipitation of the solar atmosphere in the (supposed) subtle air of the upper Earth atmosphere ${ }^{41}$. The idea behind the Mairan system had been expressed at the end of the seventeenth century by JeanDominique Cassini in connection with his discovery of zodiacal light, supposedly reflecting the presence of an extended solar atmosphere, namely a "very large sphere of atoms concentric to the Earth" that can stop and cause "the sphere of the Sun's atoms" to be assembled in abundance ${ }^{42}$. It is this concept that Mairan takes up again, building on it and introducing Newtonian attraction as the driving force behind the incorporation of solar matter into the Earth's atmosphere. Based on the fact that the apex of the zodiacal light frequently deviates from the Sun by an angle greater than $90^{\circ}$, which shows that it can extend as far as the Earth's orbit at certain times, Mairan argues that, when the Earth passes through the solar atmosphere, it must be attracted to it within a certain distance which he calculates by balancing the gravitational forces of attraction of the Earth and the Sun, determined according to Newton's Law of Universal Attraction. In the Cartesian vision shared by Mairan, the atmosphere of the Sun is made up of a large number of parts of different sizes. This heterogeneity must necessarily translate, according to Mairan, into a stratification of the solar matter that precipitates in the atmosphere, generating the horizontal and vertical structures of the aurora, explained by a combination of vertical stratification, and movements of falling matter from the upper layers to the lower layers.

Euler did not believe that the solar atmosphere could extend far enough from the Sun to precipitate into the Earth's atmosphere, as Mairan believed. On the other hand, he noted a

\footnotetext{
${ }^{41}$ Op. cit. in $\mathrm{n} .30$.

42 Jean-Dominique Cassini, « Découverte de la lumière céleste qui paraît dans le zodiaque », Recueil d'observations faites en plusieurs voyages par ordre de Sa Majesté pour perfectionner l'astronomie et la géographie, Paris, Imprimerie Royale, 1693.
} 
resemblance between the aurora and the tails of comets, in terms of texture. As soon as he arrived in St. Petersburg, he had to become acquainted with Mayer's theory, and could only share Mayer's doubts, especially as he was necessarily led to interact with him on the subject during the year 1729. For Euler, who followed the opinion expressed by Kepler a century earlier on the basis of his atmospheric refraction model, the height of the Earth's atmosphere did not exceed one German mile ${ }^{43}$, i.e. about $6 \mathrm{~km}$. The atmosphere is therefore for him a very thin film of air covering the Earth, the height of which gives an idea of the typical maximum altitude up to which small clouds responsible for Northern Lights may be present, in the theory defended by his colleague Mayer. This certainty, anchored in Euler, that the atmosphere is thin, and the mathematical plausibility of the method developed by Mayer to estimate the height of the aurora, one hundred times higher than that of the thin atmosphere he imagined, logically led Euler to reject Mayer's theory.

Euler developed his own theory, which he sought to make compatible with the considerable height of the aurora borealis, which he did not doubt. This theory is astronomical in nature, Euler placing the aurora very high above the Earth's thin atmosphere. Mairan, in order to solve the difficulty represented by the great height of the aurora, imagined the presence at high altitude of subtle, extremely light air that mixes with solar matter. Not believing in the extension of the solar atmosphere, Euler had no reason to retain Mairan's hypothesis, and he preferred to imagine auroral matter as a tail of the Earth's atmosphere, much like cometary tails; he envisages the atmospheric particles being "pushed" by sunlight (following a mechanism which he finds difficult to imagine, as he does not believe in Newton's corpuscular description of light), moving away at a very great distance (tens of thousands of

\footnotetext{
${ }^{43}$ Op. cit. in n. 39 .
} 
kilometres) and getting lost forever in planetary space. In his explanation of comet tails, which he believed to be made up of cometary matter pushed by solar rays, Euler followed in the footsteps of Kepler, who had had the same idea. Euler explains the great value of the height of the atmosphere deduced from the duration of twilight (according to him, $180 \mathrm{~km}$, in reality $70 \mathrm{~km}^{44}$ ) by the diffusion generated by the air particles escaping under solar thrust, and therefore, according to him, the same mechanism is responsible for the aurora borealis. In his memoir of 1746, he explains in a similar way the zodiacal light ("tail" of the Sun), the cometary tails and the aurora borealis ("tail" of the Earth). All three phenomena are for him the manifestation of the same physical effect, i.e. the thrust exerted by the Sun's rays on the subtlest part of matter that surrounds the bodies subjected to its radiation.

This theory, which has the merit of allowing the presence of atmospheric matter at very great heights above the atmosphere, was nevertheless quickly perceived as untenable, in particular because it does not correctly account for the observed structure and dynamics of the aurora. It predicts too high an altitude for the phenomenon, and it is also difficult to understand why the matter continuously torn out of the atmosphere by the Sun's rays forms lumps of matter detached from the atmosphere, whereas the auroral light should instead form a continuum that gradually diminishes towards the top. Euler's theory, which was quickly put to the test with arguments that are difficult to contest, notably by Mairan himself in the second version of his treatise on the aurora borealis, was considered, for example by Biot ${ }^{45}$, as the creation of a pure mathematician, with little concern for the observed realities of nature. A compared schematic view of the systems proposed by Mayer, Euler and Mairan, is shown in Figure 1.

\footnotetext{
${ }^{44}$ Philippe de la Hire, « Sur la hauteur de l'atmosphère », MARS 1713 (1739), 53-64.

${ }^{45}$ Jean-Baptiste Biot, «Considérations sur la nature et les causes de l'Aurore boréale », Journal des Savans (1820), 342-354.
} 


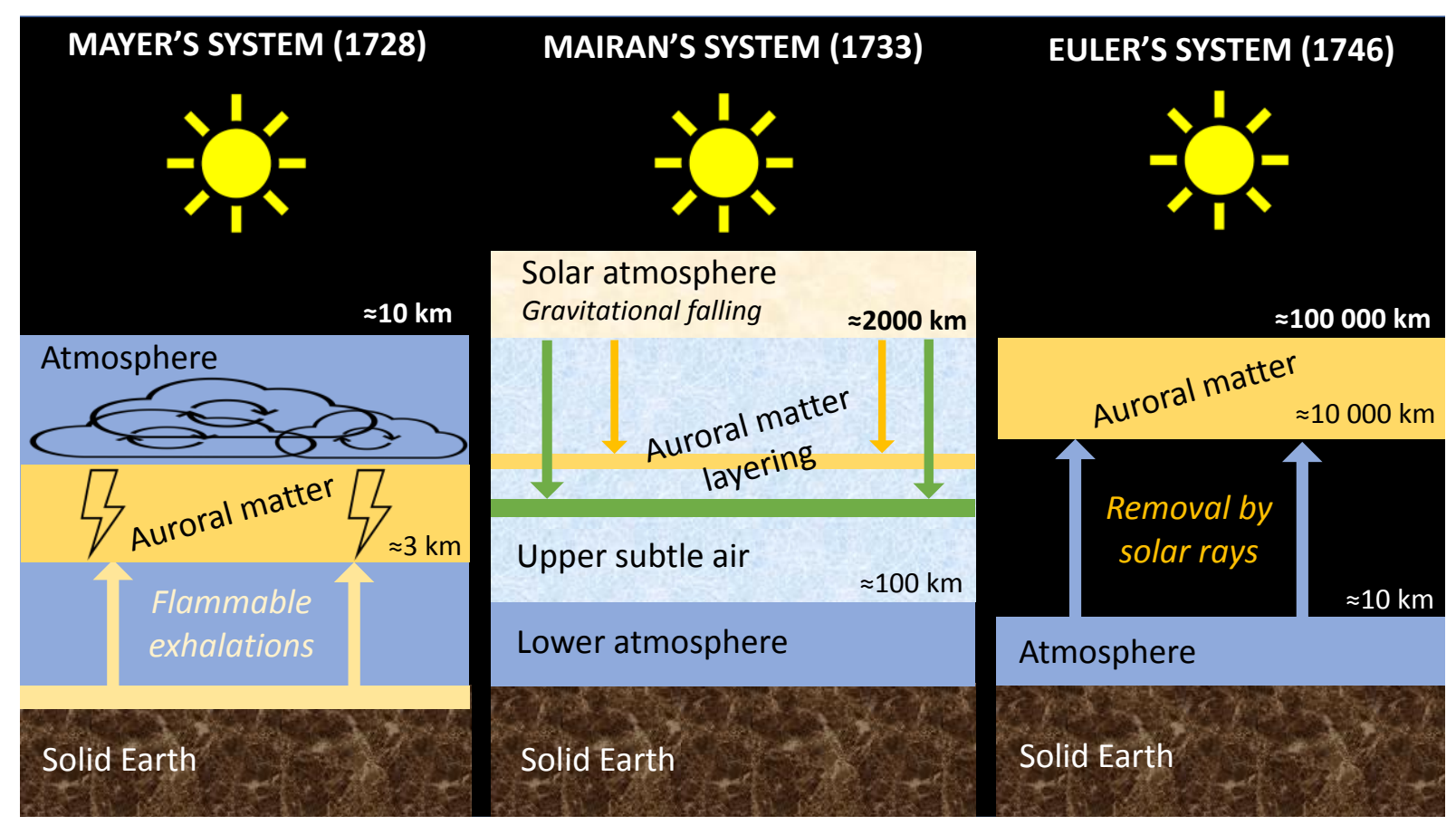

Figure 1: Schematic views of aurora borealis systems proposed by Mayer, Mairan and Euler.

\section{Discussion}

The lasting reappearance of the aurora borealis in 1716 , in a period marked by the spirit of the Enlightenment and the development of experimental physics, generated intense observation activity throughout Europe and the Russian world for half a century. The recurrence of the auroras, their seasonality, the variability of their shapes and colours, called for patient observation and the progressive accumulation of observational data in order to elucidate their causes. In his preface to the Histoire de l'Académie Royale des Sciences of $1699^{46}$, Bernard le Bovier de Fontenelle, Perpetual Secretary of the Academy of Sciences, calls for the systematic collection of "truths of Mathematics \& Physics, at random, without consideration for what will become of them" because Systematic Physics must wait until Experimental Physics can provide it with the

\footnotetext{
${ }^{46}$ Bernard Le Bovier De Fontenelle, «Préface », HARS, 1699 (1732), i-xix.

${ }^{47}$ « des verités de Mathématique $\&$ de Physique au hazard de ce qui en arrivera »
} 
necessary materials before it can erect edifices" ${ }^{48}$. The aurora borealis, like meteorological phenomena, are so complex that any development of a system that is not based on seeking coherence between a large number of observations would be reduced to conjecture. Very quickly, the observation of the Northern Lights becomes, like meteorological records, a service task in astronomical observatories. Scientists also looked to the past and to records of the aurora borealis that had occurred during the previous millennium ${ }^{49}$. Fontenelle was not hostile to the creation of systems, as these constitute the finished form of knowledge, he simply considered it premature, in the state of knowledge at the turn of the 18 th century ${ }^{50}$, and advocated the patient collection of observational data before any attempt to "make a system". It is in this spirit that, in 1721, after six years of regular observation of the aurora, JeanPhilippe Maraldi believed he noticed a correspondence between the occurrence of the aurora and climatic drought ${ }^{51}$, which prompted him to attribute the aurora borealis to the ignition of exhalations rising from the Earth, linked to weather conditions. For him, as for Descartes and then Wolff, the aurora borealis is an atmospheric phenomenon. Ten years later, Jean-Jacques Dortous de Mairan found a correspondence between the occurrence of the aurora and the distance of the Earth from the Sun, which varies slightly along its orbit; this put him on a path to find an explanation in terms of the interaction between the atmospheres of the Earth and of the $\mathrm{Sun}^{52}$, as previously explained. François de Plantade, of the Société Royale de Montpellier, who, in a memoir on the aurora borealis of 1726, had put forward an explanation

\footnotetext{
48 «pourront être un jour les fondements d'un Systême, car il faut que la Physique systématique attende à élever des Edifices, que la Phisique expérimentale soit en état de lui fournir les materiaux nécessaires ».

${ }^{49}$ See e.g. Op. cit. in n.30.

${ }^{50}$ Simone Mazauric, Fontenelle et l'invention de l'histoire des sciences à l'aube des Lumières, Fayard, 2007.

${ }^{51}$ Jean-Philippe Maraldi, « Observations de deux météores », MARS, 1721 (1723), 231-245.

${ }^{52}$ Op. cit. in n. 30 .
} 
in terms of magnetism, was refused publication of his memoir by the Paris Academy on the grounds that he had shown too much haste in putting forward a system ${ }^{53}$. As one can see, the doctrine on the subject at the French Academy of Sciences was strict, and scholars had to stick to it.

The great spatial extent of the aurora means that it is necessary to simultaneously process observations acquired from one end of the European continent to the other in order to derive the full scientific benefit. This imperative encouraged certain scientists, such as Joseph Nicolas Delisle in St. Petersburg, and Anders Celsius in Uppsala, during his great European voyage in the $1730 \mathrm{~s}^{54}$, to set up a Europe-wide network for exchanging the results of these observations. The observation of the Northern Lights generated collaborations that transcended the philosophical divide between Cartesians and Newtonians, in a period when Newtonianism was penetrating the European continent ${ }^{55}$. Great observers of the aurora, such as Delisle and Celsius, both convinced Newtonians, refrained from proposing an explanation for the phenomenon, agreeing on this question with Fontenelle. They shared their data with mechanistic scholars such as Jean-Jacques Dortous de Mairan, author of a system that he claimed was outside the dominant currents of thought, borrowing from both Descartes and Newton ${ }^{56}$. The aurora borealis thus constituted a particularly unifying theme around which many scholars of all philosophical convictions were united. The work initiated in St.

\footnotetext{
${ }^{53}$ Junius Castelnau, Mémoire historique et biographique sur l'ancienne société royale des sciences de Montpellier, Montpellier, Boehm, 1858.

${ }^{54}$ Tõnu Viik, "Anders Celsius - mees, kellelt saime temperatuuriskaala”, Geodeet, 42, 2 (2012), 66-75, french translation by Suzanne Héral available at http://viik.planet.ee/Celsius FRENCH.pdf.

${ }^{55}$ Pierre Crépel, Christophe Schmit, Fabrice Ferlin, Hugues Chabot, Autour de Descartes et Newton, Introduction, Hermann, 2017.

${ }^{56}$ See the analysis made by Stéphane Le Gars, « Dortous de Mairan et la théorie des aurores polaires: trajectoire et circulation d'une idée, de 1733 à 1933 », Revue d'histoire des sciences, 68 (2015), 311 333.
} 
Petersburg by Mayer on the explanation of the aurora borealis and the estimation of its height, taken up first by Krafft, then by Gottfried Heinsius, a geographer and astronomer from Leipzig recruited in 1736 to assist Delisle at the Observatory, constitutes the first study of this type in Russia ${ }^{57}$. Mayer's system is mixed, borrowing both from Descartes, who proposed that the aurora light was reflected by cloud particles ${ }^{58}$, and from Wolff's or Maraldi's system, which held that the ignition of exhalations rising in the atmosphere was a source of light. The dispute between Wolffians and Newtonians at the Imperial Academy of Sciences in St. Petersburg does not seem to have extended to the small community of aurora observers at the Observatory, made up of scientists from both sides (Delisle and his brother, on the one hand, Mayer and Krafft on the other), the observational approach, in St. Petersburg as elsewhere, transcending clans that were divided only on the causes of the phenomenon.

We know very little about Mayer. As a former student of Bilfinger, he was almost certainly a Leibnizian. We know that he was a specialist in mathesis, and was recognised as such at the Academy. Mathesis is a concept from Greek antiquity, taken up by Descartes, then Leibniz. It is the hypothesis of a universal science, based on the model of mathematics, which makes it possible to describe the world in a rigorous way ${ }^{59}$. The fact that Mayer does not question his system, despite the flagrant contradiction with the great heights of auroral matter predicted by his mathematical method, and the disinterest he shows in the auroral observation reports he has to write up on a daily basis, seem to indicate an approach of an a priori nature, giving preeminence to deductive reasoning and neglecting observations. Is such an approach the consequence of Mayer's philosophical conceptions, notably his commitment to mathesis, or is it the result of a mind naturally more turned towards the imagination than towards the real

\footnotetext{
${ }^{57}$ Op. cit. in n.6.

${ }^{58}$ Op. cit. in n.7.

${ }^{59}$ Op. cit. in n. 19.
} 
world? We do not know. As a practitioner of mathesis, it seems most likely that Mayer was a Leibnizian. He seems less close to Wolff, whose philosophy of nature is similar to that of the French scientists of the Academy of Sciences, such as Fontenelle, whom we have quoted, or Mairan, who advocated systematic physics, where observation serves as a basis for the elaboration of systems. But, while for Mairan systems can only come in a second stage, after having collected numerous observations, for Wolff, the collection of data and the elaboration of theory are largely simultaneous and interdependent activities ${ }^{60}$. Conceptualization within a hypothesis constantly guides the observer in his choice of observations to be made, and in return new observations lead to a revision of the hypothesis in case of disagreement between theory and observation; Wolff uses the example of astronomy to illustrate his point. In passing, we note that Mairan does not say anything else in his preface to the Dissertation on Ice of $1749^{61}$ :

In vain it will be said that the systematic spirit has always made the Philosophers fall into the greatest errors. Nevertheless, this spirit is the most precious thing in us, the most necessary to attain the most sublime knowledge, as well as to carry out the greatest things. For what would this spirit consist of, if not this natural disposition, turned in us into the habit of building a reasoned plan of our subject, a whole constructed from its components, based on what is known to us, in order to rise from there by degrees to what we do not know, \& what it is important for us to know? ${ }^{62}$

\footnotetext{
${ }^{60}$ Alberto Vanzo, "Christian Wolff and experimental philosophy," Oxford Studies in Early Modern Philosophy 7 (2015), 225-255.

${ }^{61}$ Jean-Jacques Dortous De Mairan, Dissertation sur la Glace, ou Explication Physique de la formation de la Glace, \& de ses divers phénomènes, Paris, Imprimerie Royale, 1749.

${ }^{62}$ «En vain dira-t-on que l'esprit systématique a fait tomber de tout temps les Philosophes dans les plus grandes erreurs. Cet esprit n'en est pas moins tout ce qu'il y a en nous de plus précieux, de plus nécessaire pour arriver aux connoissances les plus sublimes, comme pour exécuter les plus grandes choses. Car en quoi consisteroit-il cet esprit, si ce n'est dans une disposition naturelle tournée en
} 
Thus Wolff's natural philosophy is close to that developed by the French Cartesians of the Royal Academy of Sciences in the first half of the 18th century. Wolff, who himself advanced a system of the aurora borealis as early as 1716 , found a successor in Mayer, who took up the same idea that the aurora and the clouds are of the same matter. Mayer did not hesitate to publish this idea quickly, in line with Wolff's doctrine which authorized the introduction of hypotheses at all stages in the study of a phenomenon. It is in this respect that he can be described as Wolffian. But he does not draw all the lessons from Wolff's philosophy, which states that "if a hypothesis is incompatible with a single observed phenomenon, it must be abandoned"63. Instead of modifying his hypothesis, Mayer abandons the entire undertaking, either because he loses interest in the problem, or because he decides to give reason precedence over experience.

In a way, it fell to Leonhard Euler, who met Mayer at that time at the Observatory, to propose a system compatible with the great height of the aurora some twenty years later. In the dispute between Newtonians and Wolffians at the Imperial Academy of Sciences in St. Petersburg, Euler, initially reserved, ended up, from 1736 onwards, on the side of the Newtonians, Delisle and Bernoulli, against the theory of the Leibniz monads ${ }^{64}$. In the early 1730 s, he helped Delisle by recording astronomical observations in the diary of the St. Petersburg Observatory. From the end of 1734, he made independent observations for the construction of the meridian

\footnotetext{
habitude à nous faire un plan raisonné de notre objet, un tout de ce qui le compose, d'après ce qui nous en est connu, pour monter de-là par degrés à ce que nous en ignorons , \& qu'il nous est important d'en connoître?»

${ }^{63}$ Op. cit. in n.60.

${ }^{64}$ Op. cit. in n.3.
} 
tables, which he published the following year ${ }^{65}$. From that time on, he also participated in a growing number of technical projects on magnetism, machinery, shipbuilding and education. Although carrying out few experiments and observations himself, he attaches great importance to the validation of the results of mathematical calculations through experiment, which is obviously necessary for the success of applied projects. In his Letters to a Princess of Germany, concerning the testing of Newton's tidal theory against Descartes ${ }^{66}$, he expresses very clearly the need to proceed through experiments in order to arrive at the right theory. Euler is familiar with Mayer's work on the mathematical determination of the height of auroral matter (a few hundred kilometres), which is much higher than the height of the atmosphere, which he believed, in accordance with Kepler, to be low (a few kilometres); this led him to believe that the aurora borealis was a phenomenon outside the atmosphere. It was on this premise that he built his mathematical model, true to his principle of using mathematics and experiment in combination. Admittedly, his work is sometimes approximate, as in the estimates he makes of the geometric characteristics of the atmosphere, resulting in the aurora being too high and not explaining its polar location, but he has the audacity to question the atmospheric character of the aurora, something that only Halley before him had done thirty years earlier by attributing a magnetic origin to them ${ }^{67}$.

In the meantime, in the early 1740s, Anders Celsius and Olof Peter Hiorter highlighted the link between the aurora borealis and magnetism through a long series of observations of the

\footnotetext{
${ }^{65}$ Op. cit. in $\mathrm{n} .3$.

${ }^{66}$ Leonhard Euler, Letters of Euler on Different Subjects in Natural Philosophy. Addressed to a German Princess (sent from 1760 to 1762 and first published in three volumes from 1768 to 1772), with notes and a life of Euler by David Brewster, 2 vols., New York: Harper \& Brothers, 1840 and 1872.

${ }^{67}$ Op. cit. in n.9.
} 
irregular agitation of the magnetic needle during the aurora ${ }^{68}$, a discovery that should have returned Halley's system to the fore. However, from the beginning of the 1750s, with the discovery and exploration of atmospheric electricity, the electrical theory, developed independently by John Canton in England ${ }^{69}$ and Mikhail Vasilevich Lomonosov at the Imperial Academy of Sciences in St. Petersburg ${ }^{70}$, overshadowed all previous hypotheses. It was not until the beginning of the 20th century that the phenomenon was fully understood ${ }^{71}$, borrowing from magnetic, solar and electrical theories.

\section{Conclusion}

It must be stressed that the explanation that Mayer lost interest in the aurora borealis because of a fundamental doubt about the truth of the observations comes from Mairan himself. Mairan, a great expert on the Northern Lights, was a contemporary of Mayer, and had an ongoing correspondence with Delisle, and there can be no doubt that he speaks with knowledge of the facts. Indeed, it has been verified that Mayer's accounts of the aurora borealis in his notebooks are laconic ${ }^{72}$, especially when compared to those of Krafft, who took over the task after Mayer's death at the end of 1729 . We also note the credit given to

\footnotetext{
${ }^{68}$ Jean-Baptiste Biot, «Considérations sur la nature et les causes de l'Aurore boréale », Journal des Savans (1820), 342-354.

${ }^{69}$ John Canton, "Electrical experiments, with an attempt to account for their several phænomena; together with some observations on thinder-clouds", Philosophical Transactions of the Royal Society of London 48 (1753), 350-358.

${ }^{70}$ See for example: L. S. Yevlashin, G. V. Starkov And S. A. Chernous, "M.V. Lomonosov and the Study of Polar Aurorae", Geomagnetism and Aeronomy 26, 6 (1986), 749-752, English translation available at https://arxiv.org/ftp/arxiv/papers/1709/1709.08847.pdf .

${ }^{71}$ Kristian Birkeland, The Norwegian Aurora Polaris Expedition, 1902-1903, Volume 1, Christiana, Aschehoug \& Co, Leipzig, Johann Ambrosius Barth, London, New-York, Longmans, Green \& Co, Paris, C. Klincksieck, 1908.

${ }^{72}$ Op. cit. in $\mathrm{n} .18$.
} 
Mayer's mathematical method for estimating the height of the aurora borealis by renowned scientists such as Maupertuis and Boscovich. There is no indication that the scientific community was disinterested in Mayer's work, which might have caused him to abandon it, quite the contrary in fact. Mayer does not believe in his observations, but seems to have a great level of confidence in his aurora borealis system, inherited from Wolff, at least enough to publish it in the Commentarii. Perhaps he gives pre-eminence to reason for philosophical reasons, as a disciple of Leibniz and a practitioner of mathesis. We are lacking the elements to be sure of this. Moreover, we note that such a pre-eminence is not part of Wolff's philosophy of nature.

Acknowledgements: We would like to thank in particular Christophe Schmit, from the SYRTE laboratory, for his sound advice, and François Mottais, from the THEMAM laboratory, for his translation of Georg Friedrich Mayer's dissertation. We are indebted to Rhoda Allanic for her help in improving the English of this article. Our thanks also go to the Referees, and to the Editor, for their constructive suggestions which made it possible to significantly improve the paper. 


\title{
Appendix 1: Regarding the polar lights, by Brother Christian Mayer ${ }^{73}$
}

\author{
Translation from Latin by François Mottais ${ }^{74}$
}

I) Since the appearance of lights is so frequent in our northern regions that even the common people are not amazed by it anymore, it was easy for me to collect, over a short period of time, a large number of observations that I provide in this account along with my own thoughts about the origins of polar lights, thoughts that I have decided, as they are new, to submit to the public judgment of scientists so that I might learn from somebody else what these thoughts are worth.

II) I have decided to treat my subject as follows: firstly to give a short description of the phenomena based on all of the observations that I have been able to obtain to date; then, in order to draw a few conclusions from these observations, I try to penetrate the secrets of these polar lights using the principles of physical science as a way to support my thesis.

III) Because they appear under two types of manifestations, two kinds of polar lights can be determined. The first kind is common and more frequent in our regions: shaped like an arc, it is located in the north and emits rays that look like light beams upwards and shines with a quiet light. The second kind, which is rarer, is turned towards the sky, of which it occupies every region, and is fragmented into different parts wherein beams, that are either very short or non-existent, are most commonly fixed. The splendour of this kind of polar lights, as it is often thought, is that it undulates or trembles. It shall be made clear below that these two kinds are not in themselves different but that the two appearances are only a function of place.

IV) The following phenomena are associated with the first type of polar lights:

1. A shining arc turned towards the north, set in such a way that its concave part looks towards the horizon and the convex one towards the top.

2. The upper part of the arc always occupies, for us, the exact north.

3. The legs of the arc usually touch the horizon.

4. The higher the arc, the more extended the legs.

5. I have never observed an arc higher than 40 degrees and legs wider than a half-circle.

\footnotetext{
${ }^{73}$ Op. cit. in n. 25 .

${ }^{74}$ Member of the THEMAM/ARSCAN team at Université Paris Ouest Nanterre la Défense.
} 
6. The lower the arc, the more proportionate and regular its roundness; usually, the higher the arc, the more imperfect it becomes because of the cracks, gaps, prominences, curves etc. that occur within it. Sometimes, without its height being affected, an arc that lacks harmony gradually returns to a smooth shape and vice-versa.

7. It often happens that new arcs are created that are frequently higher or lower than an older arc but which always unite with it: this phenomenon means that the arc seems to get higher or lower.

8. However, an arc sometimes gets higher or lower without other observable arcs uniting with it.

9. The space between an arc and the horizon that is enclosed is always shrouded in darkness; yet it transmits the stars' rays in a particularly radiant way, unless it is full of black clouds.

10. The inside edge of the arc is usually dark, the outside one luminous but it is impossible to distinguish the meeting point between light and darkness as they gradually merge into one another.

11. Light beams and sometimes very broad luminous trails occur on the outside margin of the arc and they shine a bit less than the arc itself. But it happens very often that this part of the arc, from whence the beams exit, shines more than the rest.

12. All spread in a straight line towards the top which they often attain or sometimes seem to pierce.

13. Every beam has approximately the same width at its base as at its top.

14. Every beam shines with approximately the same brilliance, except that it appears that a beam is sometimes ${ }^{75}$ brighter close to the arc than it is near its summit.

15. The duration of a beam is short and uncertain; it is usually about ten seconds of time.

16. Their appearance and disappearance are most often spontaneous, yet sometimes they appear close to the arc before appearing at the top and sometimes this order is reversed; in the same manner, they disappear in one way or another.

17. Sometimes, but rarely, they are not complete and seem to be into pieces, as if they were scattered.

18. Often they move either eastwards or westwards; sometimes rather slowly, sometimes rather quickly; sometimes one beam is quicker than another in such way that

${ }^{75}$ Sic. 
they follow one another or get ahead one another in their progression. But meanwhile neither the straightness nor the impetus of the beams towards the top is changed.

19. They are sometimes present in small numbers or even absent in spite of the presence of a luminous arc; sometimes they are present in such huge numbers that the arc looks like a comb.

20. It often happens that many beams appear at the same time and, conversely, that they disappear at the same time.

21. Stars appear from everywhere, except on the dark inside margin of the arc, which, if present, covers the stars.

22. It often happens that some clouds appear, higher than the ones that the polar lights leave beneath themselves; the phenomenon becomes evident because of their different colours and movements: indeed it is impossible that clouds observed in the same area of the sky are carried and illuminated in a different way, unless they are very distant from the Earth because of their height. ${ }^{76}$

V) The following phenomena are associated with the second kind of polar lights:

1. At first sight, the sky seems to burst into flames, a trembling, radiant light appears in approximately that same way that a trembling light does when it roams in a pile of hot coals ; but this radiance is sometimes very visible, sometimes less so, and sometimes hardly visible at all.

2. Upon further inspection, one may notice small shiny clouds scattered here and there. This observation is sometimes easy, sometimes hard, depending on whether these clouds are dense or thin and, similarly, on whether they burst into flames slowly or quickly.

3. As I happened to observe a small cloud of this kind that was attaching to the top and that at once was bursting into flames and, conversely, was soon dying out, I observed that this small cloud, immediately afterwards, having become darker, was gradually moving away, leaving under it a cloud that was darkening and that eventually hid it.

4. In the same way, I later observed and understood that, regarding some other small clouds, in the interval between when they burst into flames and die out, they do not change their location nor their shape, or hardly so.

5. Once they burst into flames, they stay this way for approximately the same length of

\footnotetext{
${ }^{76}$ So he considers that the colours and movements peculiar to these clouds are a sign that they are located higher, and so further from the observer than the other. This inference is based on reason.
} 
time that the beams of the other kind of polar lights last (cf. $\left.\S \mathrm{IV}, \mathrm{n}^{\circ} 15\right)$.

6. The small clouds that are far from the top sometimes emit beams of light, but these are short and thin; the closer they are to the top, the shorter they are.

7. On the basis of other people's reports, I know that sometimes dark thunderbolts are sprinkled with similar radiances.

8. I have rarely observed this kind of polar lights on their own: almost always there occurs, linked to these polar lights, polar lights of the first kind, which I previously described; one precedes or follows the other.

9. The light of these small clouds is greater than that usually present in an arc.

10. This light is often stronger on the horizon side than on the top, so that the horizon sometimes shines from everywhere, more or less in the same way that polar lights do (cf. §IV).

VI) The following phenomena are common to both kinds of polar lights:

1. The two kinds of polar lights usually appear between the autumnal equinox and the spring equinox: indeed I never seen any during the summer.

2. More often the clouds follow the light, being at first arranged in the form of scales, then growing and accumulating little by little.

3. The two kinds of polar lights tend to appear, most often, in a clear or semi-clear sky; however, I once observed polar lights in dense clouds which covered up every part of the skies, except for some gaps here and there.

4. Their radiance is pale or whitish.

5. Their light ordinarily moves, under the effect of a light wind, towards any region of the sky which is, however, always opposite the region towards which the wind, in the lower part of the air, is blowing. Up until now, I have never experienced any example contrary to this phenomenon.

6. I have often observed that mild weather precedes or accompanies the polar lights and that ice-cold weather follows them.

7. If it occurs, as it frequently does, that polar lights appear for a certain number of consecutive nights, the successive lights subsequently become weaker, until the point where they are barely visible.

8. The duration of the light of polar lights of both kinds is very variable; it often lasts for the whole night, often a few hours, depending on whether the air is calm or disturbed.

VII) Based on the analysis of the above-mentioned phenomena, I conclude that these two kinds differ in appearance only. Most of their characteristics are in fact shared (cf. §VI) 
and if we might think that some are particular to one kind of polar lights, this is, as I shall explain later, only because of the diversity of the places, a diversity which is itself observed (cf. $\S$ III, $\S$ IV, $n^{\circ} 1,2$ and $3, \S \mathrm{V}, \mathrm{n}^{\circ} 1$ ).

VIII) Regarding the light beams, I assert that they are generated by the reflection of rays emitted by a luminous matter which is not present at the place where we see the beams. All that we see, we see under the effect of direct, refracted or reflected rays: if the beams were seen under the effect of direct rays, their light matter, spread over a vast space 1) would have to be visible, for any observer, on vertical planes (based on the observation mentioned in $\left.\S \mathrm{IV}, \mathrm{n}^{\circ} 12\right)$, but these planes at other observation sites, are inclined towards the horizon; it would therefore follow that the matter would be simultaneously linked to vertical planes and to inclined planes, which is impossible ${ }^{77} .2$ ) This matter would have to be wider in the places far from the observer, and proportionally narrower in closer places: in fact, in different places the widths could not appear equal in all places (cf. IV, $\mathrm{n}^{\circ} 13$ ) and, for different observers, this variability in width should be variable at the same time (as is established by optical laws) and the matter should be disposed as a function of the locations of the different observers; but this is impossible, so a direct line vision of the beams is impossible. If, instead of different locations, one groups together a certain number of phenomena observed by the same observer at different times, one must draw the same conclusion, because there is no reason why all the fires would always be disposed in a constant direction towards the same observer. If the vision were due to refraction, then there should be light matter beyond the region of the vapours causing the refraction, light matter which would sometimes burst into flames and sometimes die out (cf. $\S$ IV, $n^{\circ} 3$ and 4), which would be troubled by the winds (cf. $\S \mathrm{VI}, \mathrm{n}^{\circ} 5$ ), which would leave behind thick vapours (cf. $\S$ $\mathrm{V}, \mathrm{n}^{\circ} 3 ; \S 6 \mathrm{n}^{\circ} 2$ ) and which would sparkle (cf. $\S \mathrm{V}, \mathrm{n}^{\circ} 7$ ); and all of these elements do not seem to apply to this region. I add that the sun, the moon and the brighter stars should sometimes also emit similar beams by refraction; but this is something that never occurs in this way, and could never occur by virtue of the optical principles, and can be demonstrated by similar cases. Vision by refraction is thus excluded too and only vision by reflection remains, and this is yet to be proven.

\footnotetext{
${ }^{77}$ Note that in order for the tilt to be significant, the polar lights have to take place quite far to the north (or south), which implies that it takes place at great height so that it is visible in spite of the roundness of the Earth.
} 
IX) I speak about the location of the light matter, since in this region of the air there is a place where the clouds usually stop. Indeed, the dark, lower edge of the arc, with which the bright edge is always contiguous, must be regarded as a cloud or as vapour (cf. §IV, $\mathrm{n}^{\circ} 10$ ), particularly because it is troubled by the winds (cf. $§ I V, n^{\circ} 5$ ), because the light itself usually goes into the clouds (cf. $\S \mathrm{VI}, \mathrm{n}^{\circ} 2$ ) or rather appears in the form of a small cloud or of luminous vapour ( $\mathrm{cf} . \S \mathrm{V}, \mathrm{n}^{\circ} 2$ ) and becomes denser towards the horizon (by virtue of what is outlined in $\left.\S 5, \mathrm{n}^{\circ} 1\right)$ : it is obvious that this matter has all the characteristics of the clouds and thus occupies the same position as them and is the same distance from the Earth.

X) In order to be able to draw more conclusions, I shall introduce a number of auxiliary principles from physics, the first of them being as follows: in calm air, the clouds are suspended in such a way that their lower surface is flat and is in every place equidistant from the Earth. Indeed, since the particular weight of the air is the same for objects equidistant from the centre of the Earth and since the clouds, formed by the same kind of vapours, stop where their particular weight matches the weight of the air, it is obvious that the clouds stop in the place that is in every part equidistant from the centre of the Earth and that they spread in a planar shape which to our eyes is parallel to the surface of the Earth, and this is even more accurate when the air is stiller.

XI) An experiment gives credence to this principle: it is established that the closer clouds are to the horizon, the flatter their base is, and this base is always parallel to the horizon; this is due to the fact that the flat and inferior part of the clouds, located high in the sky, is seen from one side and thus appears as a line.

XII) Moreover, it is established, by reasoning and by experiment, that some clouds are suspended on top of others; this is due to the flat part of a cloud being farther from the Earth than the flat part of another cloud : this can be clearly observed when polar lights appear (cf. §4, n²2).

XIII) Here is another principle: objects, which in the air have the same height, appear closer to the horizon the farther they are from the eye of the observer. These principles are borrowed from optical science, where they have been carefully demonstrated.

XIV) From the previous principle one can also understand this: if a line is suspended in the air, dropped from the top of the arc at its height, and extended following the parallel of the terrestrial globe, and in every part equidistant from the Earth, it will appear in the form of an arc, like the arc of polar lights (cf. §IV, $n^{\circ} 1,2,3$ and 4). Conversely, if a line equidistant from the Earth appears in the form of an arc of which the most elevated 
point is exactly pointing towards the north, the line will be spread in the air following a line parallel to the Earth. This is easily understood by those who are experts in optical science, so that it is possible, without a doubt, to abstain from a demonstration.

$\mathrm{XV})$ These elements being set down, I assert that the matter of the polar lights is located in the air following a line almost parallel to the surface of the Earth. Indeed, this matter is located in the region of the clouds (cf. $\S \mathrm{IX}$ ), so it is in every place equidistant from the Earth (cf. § 10). Furthermore, it appears in the form of an arc the highest point of which points towards the north (cf. $\S \mathrm{IV}, \mathrm{n}^{\circ} 1,2,3$, and 4), so that it follows, from $\S \mathrm{XIV}$, that it occupies in the air a trail that spreads following a line parallel to the Earth. But I add that this line is almost parallel because the curve of the boreal arc is not always entirely exact (cf. $\left.\S I V, n^{\circ} 6\right)$.

XVI) Furthermore, following optical science, we know that a body with an irregular, inconstant and unequal shape gives the impression of having a more regular, constant and equal shape the more it is remote from the eye; thus we understand that the boreal arc appears more exact the closer it is to the horizon (cf. $\S \mathrm{IV}, \mathrm{n}^{\circ} 6$ ). Indeed, it is farther in this case (cf. $\S \mathrm{XIII})$.

XVII) If several bodies are scattered and disjointed in any way on any flat surface, they will also look disjointed to the eye if it $^{78}$ is set perpendicular to this flat surface; but the more the eye looks at this flat surface obliquely, the more the objects will seem to group closer together, or rather they will end up looking like they form one single body; similarly the light or the colour of each object will increase and will be brighter. I assume, once again, that these principles are totally sure by virtue of optical science.

XVIII) The flat surfaces of the clouds that link together at the top are viewed in a perpendicular way, but those that are closer to the horizon are viewed from the distance and in an oblique way. This principle is understood from $\S \mathrm{X}$ and XI.

XIX) Based on these elements, I make the following proposal regarding boreal light: the matter of this light is scattered and disjointed in the small luminous clouds; but the first kind of light appears continuous (cf. $\S ?^{79} \mathrm{n}^{\circ} 1$ ) and more radiant (cf. $\S \mathrm{V}, \mathrm{n}^{\circ}$ ) ) because in this case the matter is seen from a distance and in an oblique way. As a matter of fact, since this matter is spread over a flat surface that is parallel to the Earth (cf. § IX and $\mathrm{X}$ ), it appears at the top according to the manner in which it is spread (by virtue of what

\footnotetext{
${ }^{78}$ The subject should be the eye.

${ }^{79}$ The number is erased; it should be V.
} 
is presented in $\S \mathrm{XVIII}$ and XVII), but it appears disjointed (cf. $\S \mathrm{V}, \mathrm{n}^{\circ} 2$ ) and therefore it too is disjointed. That is why the matter of the two kinds of polar lights is scattered in the small luminous clouds. But the first kind always stretches towards the horizon (cf. $\S$ IV, $n^{\circ} 5$ ), to the point that it is seen in an oblique way (cf. $\S$ XVIII), so it is necessary that it appears continuous and more radiant (cf. $\S$ XVII). QED.

XX) This being said, we understand how the phenomena that make the two kinds of polar lights different must be explained.

XXI) Now, before explaining the phenomenon of the beams, I shall start by presenting two principles. The first is as follows: if a luminous dot is set on a horizontal plane that is slightly undulated and constant in its smooth parts, it will radiate overhead and it will reflect its beams towards the on-looking eye; then a line or a light beam will appear to the eye and it will extend in a straight line towards the eye from the luminous dot. According to the optical laws, this proposal can be demonstrated; but a common daily experience can also prove it: in fact, the moon or any luminous star irradiating the surface of a quiet body of water sends back to the eye a beam similar to the one that I have described.

XXII) On this first principle is based another: what has to be the inferior part of the clouds or of the vapours, the luminous surface, reflects in turn downwards, in the form of a luminous beam, the dots which light it from below. In fact, the flat, inferior part of the clouds, is undulating, flat ${ }^{80}$ and it results from the smooth water or ice particles (cf. $\S$ $\mathrm{X})$. But I have also learnt by experience the veracity of this principle: indeed, one night, not so long ago, when a fire broke out two or three versts ${ }^{81}$ away from my home in Saint-Petersburg, woken up by the usual noise I ran to the window along with a friend in order to observe and as we lifted our eyes to the sky, we both saw a radiant white beam extending from the area of the fire area towards our eyes and towards the top of the sky, reflected by the clouds from which some snow was falling, and the beam at times grew large, at times shrank, as the fire itself increased.

XXIII) This principle is confirmed by another phenomenon that is not as rare in SaintPetersburg as it is in Germany or France. It sometimes happens, and this is a certain fact, that during winter the sun, halted as it rises or sets, projects, as it is commonly thought, a luminous shiny tail, vertically upwards, which is described in the

\footnotetext{
${ }^{80}$ Sic.

${ }^{81}$ A verst is about 0.65 miles.
} 
commentaries of the French Academy of Sciences (year 1703, p. 78); this tail is in all aspects similar to the one associated with the fire mentioned above (cf. $\S$ XXII). This tail issues from solar rays set in upward motion on the flat surface of the vapours; the rays result from the ice particles and are reflected towards the observers' eyes, in exactly the same way that the luminous beams are issued from the surface of water (cf. § XXII). XXIV)Based on these principles, I assert that the beams of polar light are issued from the reflection of the light that is present in the small luminous clouds (cf. $\S$ XIX), while these small clouds project beams upwards onto the flat surface of the very tenuous vapours that overlook them, through which light is then reflected in the form of beams. The beams are created by reflection (cf. § VIII), so they are issued from the small luminous clouds (cf. $\S \mathrm{XIX}$ ); as a matter of fact, no other light is present in the air at this time and the radiance of the beams lasts as long as the burning of the small clouds (cf. $\S \mathrm{IV}, \mathrm{n}^{\circ} 15$ and $\S \mathrm{V}, \mathrm{n}^{\circ} 5$ ). The flat surfaces of the vapours, because of their capacity for reflection, are above the small clouds, a fact that can be understood from the phenomena mentioned in $\S \mathrm{IV}, \mathrm{n}^{\circ} 4,10,11$ and 12 and also in $\S \mathrm{XII}$; consequently they form the beams in the way explained in $\S \S$ XXI, XXII and XXIII. This principle explains the phenomena mentioned in $\S \mathrm{IV}, \mathrm{n}^{\circ} 11,12,13$ and 14 and in $\S \mathrm{V}, \mathrm{n}^{\circ} 6$.

$\mathrm{XXV}$ ) And if we also assume that these flat surfaces, as overhanging as the small clouds are luminous, are troubled by a light wind, then we have explanations for the phenomena described in $\S \mathrm{IV}, \mathrm{n}^{\circ} 16,17,18,19$ and 20.

XXVI) In the same way, since the luminous matter has vapours overhead which it illuminates, but none below, the functioning of the phenomenon described in $\S \mathrm{IV}, \mathrm{n}^{\circ} 9$ becomes obvious.

XXVII) If the upper part of a liquid contained in any vessel is moved in one direction, then it happens that the lower part of the liquid, towards the bottom of the vessel, will be displaced in the opposite direction. The veracity of this principle is easily checked through reasoning and experiment. Thus it is easy to draw conclusions from this about the way the phenomenon previously mentioned in $\S \mathrm{VI}, \mathrm{n}^{\circ} 5$, works.

XXVIII) The explanations I have provided up to now have, I suppose, a degree of certitude; however, there exist other phenomena the explanations for which I do not promise to be equally certain of; I will say a few words about my opinion regarding them, but I will first remind the reader of a few auxiliary principles.

XXIX)I take it as well-established, on the basis of thunderbolts, that the air is in every part weighed down by flammable exhalations and very tenuous vapours; arising from the 
perpetual exhalations of the Earth (sulphur, nitre, salts abundant everywhere), from the capita mortua that suck from the air vitriol, salts etc.

$\mathrm{XXX)}$ If such flammable exhalations accumulate in an area too far north, they create a flame and ignite by themselves. This principle is proven by a large number of well-known physical experiments.

XXXI) As chemistry testifies, all the somewhat tenuous exhalations are accumulated in a smaller space because of the cold, some easily, others less easily. I do not speak here about the accumulation of exhalations, through which they are condensed and returned to fluid form, but rather the accumulation by which they simply gather closer together alternatively.

XXXII) As the sun moves back from the equator towards the south, the northern regions of the air end up becoming cold and they become colder the further north they are and the more the sun moves back. Moreover, regions of the air on the same parallel or of the same climate are affected by a more or less identical arrival of cold. I say more or less because there are causes other than the sun, that compete with it, but the absence of the sun is without a doubt the main cause of cold. This principle is manifest and does not require any other proof.

XXXIII) I add to this a principle that I do not dare to present as absolutely certain but that I am, however, compelled to present for posterity's benefit; this principle is as follows: the flammable exhalations, with the aid of heat, mingle and merge with the watery vapours and are then separated from them when the cold arrives, at the moment when the watery vapours gather faster than the flammable exhalations.

XXXIV) I now assert that when the Sun is in the boreal regions, or when warm winds blow, the air gets warmer and the very tenuous watery vapours are lifted up into the air and mingle with the flammable exhalations (cf. $\S$ XXXIII and $\S$ XXIX); when the sun moves back towards the south, cold takes its place and is equally distributed within the same climate (cf. § XXXII) and it gathers into small, very tenuous clouds the flammable exhalations intermixed with the watery vapours (cf. $\S$ XXI and $\S$ XIX); gradually the flammable exhalations leave these small clouds and gather above them (cf. $\S$ XXXIII); once a sufficient amount of these exhalations has accumulated, it produces a flame and catches fire (cf. $\S \mathrm{XXX}$ ); a new accumulation is formed by this ignition, it catches fire and the story repeats itself as many times as possible. I think this fits admirably with what the very famous professor Wolff said about them, when he called matter of lightning the matter of the polar lights. 
XXXV) Based on this, we easily understand how luminous matter is generated (cf. $\S$ XIX). Its positioning follows the evolution of the climate (cf. $\S \mathrm{XV}$ ) and the repeated ignitions and extinctions of the small luminous clouds are just as numerous (cf. $\S \mathrm{V}, \mathrm{n}^{\circ} 3$ and 4). It is also possible that the repeated thunderbolts which occur during the summertime have the same origin.

XXXVI) While the watery vapours are gradually left behind by the flammable exhalations, they become heavier, they stabilize and they become visible; this being established, and on the basis of what has previously been said (cf. $\S$ XVII), we understand how the phenomena described in $\S \mathrm{IV}, \mathrm{n}^{\circ} 1, \S \mathrm{V}, \mathrm{n}^{\circ} 3$ and 4 and $\S \mathrm{VI}, \mathrm{n}^{\circ} 2$ work.

XXXVII) Thus I have been able to explain almost every phenomenon that ordinarily happens during polar lights. This subject is too vast for me to exhaust, so I have been forced to state many things in concise manner so as to remain brief. If the opportunity arises and if interest in the subject allows it, I will one day be able to say more about the distance from the luminous matter to the Earth; indeed I can determine it using geometry, if I am given the height of the arc, the horizontal width of the legs and if my previously mentioned hypothesis is accepted (cf. $\S \mathrm{XV}$ ). As a matter of fact, if $q$ is the curve of the sky's elevation, $m$ the curve of the arc at its maximal height, $g$ half the width of the legs, $a$ half the diameter of the Earth and $b$ the curve of the angle equal to the maximal height of the arc and to the height of the equator taken at the same time, then the distance from the matter at the top of the arc to the observer shall be of 2 amqqgg/r(rrbb-ggqq. I will explain another time the discovery of this law and its application to examples.

XXXVIII) Finally, I am pleased to add that the polar lights were also known in more ancient times: there were men who reported numerous prodigies; there were also those who listed comets and looked for their causes. Aristotle was among those who studied comets; he described them very clearly in the first book of the Meteorology, chapters 4 and 5: he compares the light that I call vertical to a flame that appears in a field of burning stubble and he refers to the trembling flames as goats, but uses the term chasma to designate the other type of arc. This word, used at the time, refers to the interior dark space of the arc that precisely resembles a chasm. What we refer to as light beams, he calls wooden beams, and he says that they rise up from the chasma. Pliny also describes the phenomena of polar lights in the second book of his Natural History, chapters 26 and 27. Those who considered this meteor an extraordinary and astonishing 
phenomenon are very numerous. I will add two old accounts that my dear Bayer has provided to me. This first one is in the Chronicle of Edessa, folio 407 (which is contained in Giuseppe Simone Assemani's Oriental Library, volume 1), and reads as follows: "during the year 813 of the Seleucid era ${ }^{82}$, a large amount of fire was seen in the northern part of the sky, the fire burnt all night". The other testimony is that of Robert the Monk in the fifth book of his Historia Hierosolymitana of 1097, which states: "during this night, there shone a comet among other stars of the sky and it produced the rays of its own light, and between the north and the south a fiery redness lit the sky". I add to this the testimony of Marcello Squarcialupi who, in an essay about comets, provided quite a good picture of the lights which he describes as follows: "during year 1575, in the harvest month, October, the sky burnt all night, or seemed to burn. I had never seen such a thing and it is certainly something to be dreaded by all mortals. While the moon stayed hidden, a great light appeared towards Silesia and Sarmatia, just like at dawn. In the horizon there was an expanse that rose in the form of an arc, oblong; and, from the highest end of this luminous trail, arose great rays, sometimes here, sometimes there, that crossed it in straight lines. These rays stayed motionless for a long time in the shape of cones or else they disappeared and new ones suddenly appeared. And then, as I observed all this with amazement, gigantic flames shone out of the intervals between the rays, like trembling flames that rose towards the top of the sky, one after another, in a very quick race. In this place, some stayed for a while, while others soon vanished. I for my part saw, shortly before the middle of the night, some rays that were hastening from both ends of the light towards the middle of the space [the zenith] and very violently rushed against each other in opposite and opposing directions, like two enemy armies. Then there was confusion and a clashing of the rays, which bent themselves, pushing the opposing rays, sometimes taking flight, rising up and twisting themselves with an incredible variety of colours, purple, violet, yellow and red. During this celestial fight and struggle, as the oriental part started to bend, the occidental rays appeared stronger, more powerful and victorious. Those who like to believe their own stories said that there was soon to be a dreadful war between us and the Mohammedans etc." I think that here one has to relate other older and more recent stories that evoke armies, weapons, fights etc. seen in the sky.

${ }^{82}$ 501/502 AD. 